\title{
Systematics of Spallation Yields
}

\author{
G. Rudstam \\ CERN, Geneva, Switzerland \\ (Z. Naturforschg. 21 a, 1027-1041 [1966] ; received 3 March 1966) \\ Dedicated to Professor Dr. W. Gentner on the occasion of his 60th birthday
}

\begin{abstract}
Available experimental spallation data have been used to construct a five-parameter formula describing the cross-section distribution for a wide range of experimental conditions with a fair degree of accuracy. The application of the cross-section formula to different fields of research is indicated.
\end{abstract}

Numerous spallation investigations have been carried out using a great variety of experimental conditions. All these investigations taken together contain a large amount of information on spallation yields, but it is not easy to extract information useful for a specific purpose from the long lists of measured cross-sections. It is therefore important to systematize all these spallation data in order to present the material in a more perspicuous manner.

Attempts to represent the cross-sections by a suitable approximative analytical function have been made ${ }^{1}$. A simple four-parameter formula is the following:

$$
\sigma(Z, A)=\exp \left[P A-Q-R(Z-S A)^{2}\right]
$$

where $\sigma(Z, A)$ is the formation cross-section of the spallation product of atomic number $Z$ and mass number $A$. This formula corresponds to an exponential yield-mass distribution and a Gaussian charge distribution. The parameters $P, Q, R$, and $S$ should depend on the irradiation conditions, but the ones defining the charge distribution, $R$ and $S$, are found to be insensitive to the experimental conditions. The parameter $P$, on the other hand, depends strongly on the irradiation energy.

The cross-section formula as given above has been mainly used for targets in the mass-region $51-75^{1-3}$, but it has also been applied both to heavier and lighter targets ${ }^{4-6}$.

In the present work an attempt will be made to generalize the cross-section systematics to cover most

1 G. Rudstam, Phil. Mag. 46, 344 [1955] ; Inaugural Dissertation, University of Uppsala, Uppsala 1956.

2 M. Honda and D. LaL, Phys. Rev. 118, 1618 [1960].

3 M. Honda and D. LaL, Nucl. Phys. 51, 363 [1964].

4 J. R. Grover, University of California Radiation Laboratory Report UCRL-3932 [1957]. experimental conditions. Heavy ions as bombarding particles are excluded because the spallation studies with these are as yet so fragmentary that no serious test of a cross-section formula is possible. The same applies to photo-induced reactions. It turns out that by adding just one parameter to the earlier four, one can construct formulas which, with a reasonable accuracy, cover most known spallation cross-sections. The parameters of these formulas vary very regularly with the irradiation conditions, and their values for specified cases can easily be obtained thereby making the estimation of spallation yields for any experimental conditions possible.

\section{Extension of the cross-section formula}

\subsection{Form chosen for the distribution}

It is immediately apparent that the extension of Eq. (1) in the given form to a wide mass region would meet with great difficulties. In particular, it is unreasonable to expect that the position of the peak of the charge distribution, $Z_{\mathrm{p}}$, would remain proportional to the mass number. Instead, one would expect it to follow some function more or less parallel to the stability line. One of the simplest forms which can be chosen is to add one more parameter and write

$$
Z_{\mathrm{p}}=S A-T A^{2} .
$$

Grover ${ }^{4}$ presents a curve of $Z_{\mathrm{p}} / A$ versus mass number covering the mass interval $30-150$. It is

5 A. K. Lavrukhina and A. A. Pozdnyakov, J. Nucl. Energy A (Reactor Sci.) 13, 88 [1960].

6 G. D. Badhwar, R. R. Daniel, and B. Vijayalakshimi, Progr. Theor. Phys. 28, 607 [1962]. 
apparent from this curve that a linear plot would be a good approximation to $Z_{\mathrm{p}} / A$, i. e. a function of type (2) should be chosen for $Z_{\mathrm{p}}$. From Grover's curve one can deduce the following values of the parameters:

$$
\begin{aligned}
& S=0.49, \\
& T=0.00033 .
\end{aligned}
$$

It will now be assumed that the charge distribution is symmetric around its (generally non-integral) most probable atomic number $Z_{\mathrm{p}}$, and furthermore that it behaves properly close to the peak, i. e. its derivative must be zero at $Z=Z_{\mathrm{p}}$. These conditions are fulfilled for distributions of the type

$$
\sigma(Z)=k_{1} \exp \left[-k_{2}\left|Z-Z_{\mathrm{p}}\right|^{a}\right],
$$

where $k_{1}, k_{2}$, and $a$ are positive constants, provided that $a>1$. Thus exponential distributions are excluded. For $\alpha=2$ the distribution is Gaussian. Such a distribution falls off quite rapidly at the wings, however, and therefore a distribution with $a=3 / 2$ decreasing more slowly will also be investigated. A comparison with experimental data might then decide which form is to be preferred.

Equation (1) implies that the yield-mass curve is exponential. In the absence of more detailed experimental information on this point, this assumption is retained. Thus the following distributions will be considered:

$$
\begin{aligned}
& \text { CDMD-G: } \sigma(Z, A) \\
& \quad=\text { const } \times \exp \left[P A-R\left(Z-S A+T A^{2}\right)^{2}\right], \\
& \text { CDMD: } \quad \sigma(Z, A) \\
& \quad=\text { const } \times \exp \left[P A-R\left|Z-S A+T A^{2}\right|^{3 / 2}\right] .
\end{aligned}
$$

The notation CDMD alludes to the description of the cross-sections in terms of charge distributions and a yield-mass distribution. For many applications, however, it might be more appropriate to express the cross-section distribution in terms of isotopic distributions and the elemental distribution. Therefore such distributions constructed in a manner analogous to Eqs. (4) and (5), or

$$
\begin{aligned}
& \text { IDED-G: } \sigma(Z, A) \\
& \quad=\text { const } \times \exp \left[P Z-R\left(A-S Z-T Z^{2}\right)^{2}\right] \text {, } \\
& \text { and }
\end{aligned}
$$

$$
\begin{aligned}
& \text { IDED : } \quad \sigma(Z, A) \\
& \quad=\text { const } \times \exp \left[P Z-R\left|A-S Z-T Z^{2}\right|^{3 / 2}\right]
\end{aligned}
$$

will also be investigated.
The parameters appearing in Eqs. (4) to (7) have the same notation, but they are, of course, in general different.

In many investigations cross-sections of several isotopes belonging to the same element have been measured. Such data can be used for a determination of the parameters of the isotopic distributions, i. e. $R$ and $A_{\mathrm{p}}$ in the formulas

ICSD-G: $\sigma(A)=$ const $\times \exp \left[-R\left(A-A_{\mathrm{p}}\right)^{2}\right]$,

and

ICSD : $\quad \sigma(A)=$ const $\times \exp \left[-R\left|A-A_{\mathrm{p}}\right|^{3 / 2}\right]$.

By doing this for different elements and plotting $A_{\mathrm{p}} / Z$ versus $Z$, a straight line with slope equal to the parameter $T$ and intercepting the ordinate at $A_{\mathrm{p}} / Z=S$ should result. The parameters $R$ in (8) and (9) should be identical to $R$ of Eqs. (6) and (7), respectively.

It is, of course, quite possible that both $P$ and $R$ in the formulas (4) to (7) are mass-dependent (or atomic number-dependent), but if this dependence is weak the formulas will still be useful to describe the cross-sections within a limited mass interval.

The sum over all cross-sections should yield the total cross-section $\sigma_{i}$ for formation of spallation products. If the CDMD-G distribution is chosen as an example, one obtains

$$
\begin{aligned}
\sigma_{i}=\sum \sigma(Z, A) \sim \text { const } \\
\quad \times \int_{A_{1}}^{A_{2}} \int_{-\infty}^{\infty} \exp \left[P A-R\left(Z-S A+T A^{2}\right)^{2}\right] \mathrm{d} A \mathrm{~d} Z,
\end{aligned}
$$

where the summation is approximated by an integral using for $A$ the limits $A_{1}$ and $A_{2}$, and for $Z$ the limits $-\infty$ and $+\infty$. The latter limits can be used because of the rapid decrease of the charge distributions at the wings. Thus

$$
\sigma_{i}\left(A_{1}, A_{2}\right) \sim \text { const } \times \frac{\pi^{1 / 2}\left(e^{P A_{2}}-e^{P A_{1}}\right)}{P R^{1 / 2}} .
$$

The cross-section formulas cannot be expected to hold over the whole range of spallation products. At very low mass numbers (or atomic numbers) the exponential decrease is turned into an increase corresponding to the frequent emission of light particles either by evaporation or fragmentation. This should not be taken into account when estimating the total inelastic cross-section $\sigma_{i}$, however, because it is very likely that a heavier product is also formed, and only that one should be counted. Thus an extrapolation of the cross-section formula to $A=0$ is reasonable, nota bene if such an extra- 
polation is allowed energetically. For this a certain minimum irradiation energy is required. Also the upper limit of integration is somewhat uncertain. Therefore, a new parameter $\hat{\sigma}$ is defined as corresponding to the cross-section obtained by putting $A_{1}=0$, irrespective of this being energetically allowed or not, and $A_{2}$ equal to the target mass number $A_{\mathrm{t}}$ (weighted mass number in case of several target isotopes) in Eq. (11). The constant appearing in Eq. (4) is then related to this new parameter by the relation

$$
\text { const }=\frac{\hat{\sigma} P R^{1 / 2}}{\pi^{1 / 2}\left(e^{\left.P A_{\mathrm{t}}-1\right)}\right.},
$$

and the final cross-section formula is

$$
\text { CDMD-G: } \begin{aligned}
& \sigma(Z, A)=\frac{\hat{\sigma} P R^{1 / 2}}{\pi^{1 / 2}\left(e^{P A_{\mathrm{t}}}-1\right)} \\
& \times \exp \left[P A-R\left(Z-S A+T A^{2}\right)^{2}\right] .
\end{aligned}
$$

In this formula $\hat{\sigma}$ as well as $P, R, S$, and $T$ are regarded as free parameters to be deduced from a comparison with measured cross-sections.

For CDMD, IDED-G, and IDED similar expressions are obtained.

\subsection{Determination of the parameters of the cross-section formulas}

The parameters of the cross-section formulas have to be determined from a given set of measured crosssections corresponding to certain irradiation conditions. This can be done by the "least squares" method. As the equations are not on a linear form, the method of differential corrections has to be applied. In many cases the measured cross-sections are not primary ones but contain contributions from short-lived parents. The formulas apply only to primary cross-sections and therefore the experimental cross-sections are compared to a sum taken over a suitable number of contributing isobars.

The CDMD-G distribution is again taken as an example. Approximative values $\hat{\sigma}_{0}, P_{0}, R_{0}, S_{0}$, and $T_{0}$ are chosen for the parameters, and Eq. (13) is differentiated around these values:

$$
\begin{aligned}
& \log \sigma_{\exp }(Z, A)-\log \sigma_{0}(Z, A) \\
& =\Delta \log \hat{\sigma}+\alpha \Delta P+\beta \Delta R+\gamma \Delta S+\delta \Delta T,
\end{aligned}
$$

with

$$
\begin{aligned}
\sigma_{0}(Z, A)=\sum & \frac{\hat{\sigma}_{0} P_{0} R_{0}^{1 / 2}}{Z} \\
& \times \exp \left[P_{0} A-R_{0}\left(Z-S_{0} A+T_{0} A^{2}\right)^{2}\right] ; \\
\alpha=A+ & \frac{1}{P_{0}}-\frac{A_{\mathrm{t}} e^{P_{0} A_{\mathrm{t}}}}{e^{P_{0} A_{\mathrm{t}}-1}} ;
\end{aligned}
$$

$\beta=\frac{1}{2 R_{0}}-\frac{\sum_{Z}\left(Z-S_{0} A+T_{0} A^{2}\right)^{2} \exp \left[-R_{0}\left(Z-S_{0} A+T_{0} A^{2}\right)^{2}\right]}{\sum_{Z} \exp \left[-R_{0}\left(Z-S_{0} A+T_{0} A^{2}\right)^{2}\right]} ;$ $\gamma=2 A R_{0}$

$$
\frac{\sum_{Z}\left(Z-S_{0} A+T_{0} A^{2}\right) \exp \left[-R_{0}\left(Z-S_{0} A+T_{0} A^{2}\right)^{2}\right]}{\sum_{Z} \exp \left[-R_{0}\left(Z-S_{0} A+T_{0} A^{2}\right)^{2}\right]} ;
$$

$\delta=-A \gamma$

and

$\Delta \log \hat{\sigma}=\log \hat{\sigma}-\log \hat{\sigma}_{0} ; \Delta P=P-P_{0} ; \Delta R=R-R_{0} ;$ $\Delta S=S-S_{0} ; \Delta T=T-T_{0}$.

In this form the equation is linear in the differences $\Delta \log \hat{\sigma}$, etc., and the method of "least squares" can be applied. By adding the calculated differences to the approximate parameter values, a new set of parameters is obtained, and the calculation is repeated until the modulus of all differences is smaller than the corresponding standard deviations. The parameter values then obtained are the most appropriate ones for the cross-section formula.

A suitable measure of how well the formula represents the experimental cross-sections is the factor $e^{\varepsilon}$, where $\varepsilon$ is the root-mean-square error of $\left(\log \sigma_{\exp }-\log \sigma_{\text {calc }}\right)$. The factor $e^{ \pm \varepsilon}$, the "average error factor", is the average ratio between experimental and calculated cross-sections.

As it is very tedious to carry out the calculations by hand, the problem was programmed for the computer IBM 7090 at CERN.

\section{Application to spallation investigations}

By applying Eqs. (4) to (9) to available spallation data the variation of the parameters with experimental conditions (target element; kind and energy of bombarding particles) has been evaluated. In cases where the accuracy of the experimental crosssections is indicated these have been properly weighted. The cross-section formulas cannot be expected to hold right up to the target, and no product nearer to the target than two mass units was considered.

Tables 1 and 2 give the spallation data used in the present investigation. The average error factor $e^{\varepsilon}$ tabulated in these tables shows how successful the formulas are in representing the measured cross-sections. 


\begin{tabular}{|c|c|c|c|c|c|c|c|c|c|}
\hline \multirow{2}{*}{ Target } & \multirow{2}{*}{\multicolumn{2}{|c|}{ Irradiation }} & \multirow{2}{*}{$\begin{array}{l}\text { No. of } \\
\text { exp. } \\
\text { results }\end{array}$} & \multirow{2}{*}{$\begin{array}{l}\text { Mass interval } \\
\text { covered }\end{array}$} & \multirow{2}{*}{ Reference } & \multicolumn{4}{|c|}{$e^{\varepsilon}$} \\
\hline & & & & & & CDMD - G & CDMD & IDED - G & IDED \\
\hline V & 60 & $\mathrm{MeV} \mathrm{p}$ & 12 & $38-49$ & 7 & 2.06 & 2.09 & 2.04 & 2.05 \\
\hline V & 100 & $\mathrm{MeV} \mathrm{p}$ & 13 & $35-49$ & 7 & 1.67 & 1.75 & 1.70 & 1.76 \\
\hline V & 170 & $\mathrm{MeV} \mathrm{p}$ & 22 & $24-48$ & 1 & 1.32 & 1.45 & 1.31 & 1.52 \\
\hline V & 175 & $\mathrm{MeV} \mathrm{p}$ & 15 & $28-49$ & 7 & 1.81 & 1.88 & 1.78 & 1.95 \\
\hline V & 240 & $\mathrm{MeV} \mathrm{p}$ & 16 & $28-49$ & 7 & 2.21 & 2.34 & 2.16 & 2.37 \\
\hline Mn & 170 & $\mathrm{MeV} \mathrm{p}$ & 18 & $31-52$ & 1 & 1.37 & 1.50 & 1.36 & 1.53 \\
\hline $\mathrm{Fe}$ & 340 & $\mathrm{MeV} \mathrm{p}$ & 21 & $31-52$ & 8 & 1.52 & 1.70 & 1.52 & 1.69 \\
\hline $\mathrm{Fe}$ & 730 & $\mathrm{MeV} \mathrm{p}$ & 17 & $22-54$ & 3 & 1.39 & 1.51 & 1.40 & 1.48 \\
\hline $\mathrm{Fe}$ & 24 & $\mathrm{GeV} p$ & 18 & $22-52$ & 9 & 1.45 & 1.46 & 1.44 & 1.45 \\
\hline Co & 170 & $\mathrm{MeV} \mathrm{p}$ & 17 & $31-55$ & 1 & 1.49 & 1.47 & 1.50 & 1.54 \\
\hline Co & 370 & $\mathrm{MeV} \mathrm{p}$ & 23 & $32-56$ & 10 & 2.11 & 2.04 & 2.07 & 2.23 \\
\hline $\mathrm{Cu}$ & 49 & $\mathrm{MeV} \mathrm{p}$ & 10 & $54-61$ & 11 & 1.91 & 1.98 & 1.92 & 1.74 \\
\hline $\mathrm{Cu}$ & 90 & $\mathrm{MeV} \mathrm{p}$ & 10 & $48-61$ & 12 & 2.12 & 2.13 & 2.13 & 2.13 \\
\hline $\mathrm{Cu}$ & 190 & $\mathrm{MeV} \mathrm{p}$ & 11 & $48-61$ & 12 & 1.78 & 1.73 & 1.78 & 1.73 \\
\hline $\mathrm{Cu}$ & 190 & $\mathrm{MeV}$ d & 18 & $32-61$ & 13 & 1.66 & 1.71 & 1.70 & 1.66 \\
\hline $\mathrm{Cu}$ & 340 & $\mathrm{MeV} \mathrm{p}$ & 26 & $32-61$ & 13 & 1.77 & 1.73 & 1.78 & 1.69 \\
\hline $\mathrm{Cu}$ & 380 & $\mathrm{MeV} \propto$ & 10 & $38-61$ & 13 & 1.73 & 1.75 & 1.73 & 1.75 \\
\hline $\mathrm{Cu}$ & 400 & $\mathrm{MeV} \mathrm{n}$ & 12 & $49-61$ & 14 & 1.56 & 1.43 & 1.55 & 1.43 \\
\hline $\mathrm{Cu}$ & 660 & $\mathrm{MeV} \mathrm{p}$ & 12 & $32-59$ & 15 & 1.46 & 1.53 & 1.46 & 1.54 \\
\hline $\mathrm{Cu}$ & 680 & $\mathrm{MeV} \mathrm{p}$ & 31 & $22-61$ & 16 & 2.50 & 2.44 & 2.49 & 2.46 \\
\hline $\mathrm{Cu}$ & 980 & $\mathrm{MeV} \mathrm{p}$ & 14 & $18-61$ & 17 & 1.80 & 1.72 & 1.81 & 1.75 \\
\hline $\mathrm{Cu}$ & & $\mathrm{GeV} \mathrm{p}$ & 33 & $32-61$ & 18 & 1.75 & 1.66 & 1.73 & 1.67 \\
\hline $\mathrm{Cu}$ & & $\mathrm{GeV} \mathrm{p}$ & 16 & $22-61$ & 19 & 1.22 & 1.29 & 1.22 & 1.30 \\
\hline $\mathrm{Cu}$ & & $\mathrm{GeV} \mathrm{p}$ & 43 & $18-61$ & 20 & 1.44 & 1.43 & 1.43 & 1.44 \\
\hline $\mathrm{Cu}$ & 20 & $\mathrm{GeV} \mathrm{p}$ & 16 & $22-61$ & 19 & 1.19 & 1.28 & 1.21 & 1.30 \\
\hline $\mathrm{Cu}$ & 24 & $\mathrm{GeV} p$ & 41 & $18-61$ & 21 & 1.57 & 1.64 & 1.59 & 1.66 \\
\hline $\mathrm{Cu}$ & 30 & $\mathrm{GeV} \mathrm{p}$ & 16 & $22-61$ & 19 & 1.21 & 1.30 & 1.22 & 1.31 \\
\hline $\mathrm{Zn}$ & 340 & $\mathrm{MeV} \mathrm{p}$ & 22 & $32-61$ & 22 & 1.82 & 1.85 & 1.77 & 1.86 \\
\hline As & 103 & $\mathrm{MeV} \mathrm{p}$ & 20 & $61-72$ & 1 & 1.72 & 1.71 & 1.73 & 1.81 \\
\hline As & 170 & $\mathrm{MeV} \mathrm{p}$ & 22 & $56-72$ & 1 & 1.46 & 1.46 & 1.45 & 1.47 \\
\hline As & 190 & $\mathrm{MeV}$ d & 16 & $52-72$ & 23 & 3.07 & 3.20 & 3.06 & 3.10 \\
\hline As & 380 & $\mathrm{MeV} \mathrm{p}$ & 52 & $42-73$ & 24 & 2.30 & 2.62 & 2.40 & 2.67 \\
\hline As & 590 & $\mathrm{MeV} \mathrm{p}$ & 49 & $24-73$ & 25 & 1.80 & 1.88 & 1.85 & 1.93 \\
\hline As & 2. & $\mathrm{GeV} p$ & 8 & $66-72$ & 26 & 1.13 & 1.35 & 1.14 & \\
\hline $\mathrm{Y}$ & 240 & $\mathrm{MeV} \mathrm{p}$ & 24 & $68-85$ & 27 & 3.99 & 3.89 & 3.96 & 4.00 \\
\hline $\mathrm{Nb}$ & 240 & $\mathrm{MeV} \mathrm{p}$ & 11 & $57-90$ & 28 & 1.28 & 1.30 & 1.28 & 1.26 \\
\hline $\mathrm{Nb}$ & 320 & $\mathrm{MeV} \mathrm{p}$ & 11 & $57-90$ & 28 & 1.26 & 1.27 & 1.26 & 1.27 \\
\hline $\mathrm{Nb}$ & 320 & $\mathrm{MeV} \propto$ & 11 & $57-90$ & 28 & 1.29 & 1.31 & 1.29 & 1.26 \\
\hline $\mathrm{Nb}$ & 500 & $\mathrm{MeV} \mathrm{p}$ & 11 & $57-90$ & 28 & 1.23 & 1.21 & 1.23 & 1.23 \\
\hline $\mathrm{Nb}$ & 500 & $\mathrm{MeV} \alpha$ & 11 & $57-90$ & 28 & 1.18 & 1.15 & 1.18 & 1.17 \\
\hline $\mathrm{Nb}$ & 720 & $\mathrm{MeV} \mathrm{p}$ & 11 & $57-90$ & 28 & 1.17 & 1.20 & 1.17 & 1.22 \\
\hline $\mathrm{Nb}$ & 720 & $\mathrm{MeV} \alpha$ & 11 & $57-90$ & 28 & 1.66 & 1.80 & 1.66 & 1.81 \\
\hline $\mathrm{Nb}$ & 880 & $\mathrm{MeV} \alpha$ & 11 & $57-90$ & 28 & 1.21 & 1.16 & 1.21 & 1.19 \\
\hline $\mathrm{Ag}$ & 340 & $\mathrm{MeV} \mathrm{p}$ & 48 & $61-103$ & 29 & 1.98 & 2.06 & 1.98 & 1.98 \\
\hline $\mathrm{Ag}$ & 480 & $\mathrm{MeV} \mathrm{p}$ & 36 & $57-103$ & 30 & 1.99 & 2.79 & 2.00 & 1.99 \\
\hline In & & $\mathrm{GeV} \mathrm{p}$ & 14 & $66-74$ & 31 & 1.43 & 1.33 & 1.43 & 1.36 \\
\hline $\mathrm{Sb}$ & 190 & $\mathrm{MeV}$ d & 24 & $87-118$ & 32 & 3.31 & 3.27 & 3.36 & 3.65 \\
\hline $\mathrm{Sb}$ & 380 & $\mathrm{MeV} \alpha$ & 18 & $97-118$ & 32 & 2.03 & 2.10 & & \\
\hline $\mathrm{Cs}$ & 240 & $\mathrm{MeV} \mathrm{p}$ & 15 & $95-129$ & 33 & 1.63 & 1.67 & 1.63 & 1.65 \\
\hline $\mathrm{Hf}$ & 660 & $\mathrm{MeV} \mathrm{p}$ & 25 & $134-169$ & 5 & 3.10 & 3.04 & 3.09 & 3.01 \\
\hline $\mathrm{Ta}$ & & $\mathrm{GeV} \mathrm{p}$ & 27 & $117-177$ & 4 & 1.46 & 1.59 & 1.76 & 1.83 \\
\hline $\mathrm{Bi}$ & 380 & $\mathrm{MeV} \mathrm{p}$ & 34 & $186-206$ & 34 & 2.62 & 2.68 & & \\
\hline $\mathrm{Bi}$ & 480 & $\mathrm{MeV} \mathrm{p}$ & 17 & $128-206$ & 15,16 & 2.62 & 2.59 & & \\
\hline $\mathrm{Bi}$ & 660 & $\mathrm{MeV} \mathrm{p}$ & 31 & $140-206$ & 35,36 & 2.11 & 2.10 & & \\
\hline
\end{tabular}

Table 1. Spallation data used for fitting CDMD-G, CDMD, IDED-G, and IDED-distributions. 


\begin{tabular}{|c|c|c|c|c|c|c|c|}
\hline \multirow{2}{*}{ Target } & \multirow{2}{*}{\multicolumn{2}{|c|}{ Irradiation }} & \multirow{2}{*}{ Element studied } & \multirow{2}{*}{$\begin{array}{l}\text { No. of exp. } \\
\text { results }\end{array}$} & \multirow{2}{*}{ Reference } & \multicolumn{2}{|c|}{$e^{\varepsilon}$} \\
\hline & & & & & & ICSD-G & ICSD \\
\hline V & 170 & $\mathrm{MeV} \mathrm{p}$ & $\mathrm{Sc}$ & 5 & 1 & 1.25 & 1.28 \\
\hline V & 590 & $\mathrm{MeV} \mathrm{p}$ & $\mathrm{K}$ & 5 & 37 & 1.32 & 1.86 \\
\hline $\mathrm{Fe}$ & 590 & $\mathrm{MeV} \mathrm{p}$ & $\mathrm{K}$ & 5 & 37 & 1.19 & 1.11 \\
\hline $\mathrm{Fe}$ & 600 & $\mathrm{MeV}$ p & A & 6 & 38 & 1.16 & 1.05 \\
\hline $\mathrm{Fe}$ & 24 & $\mathrm{GeV} \mathrm{p}$ & $\mathrm{Sc}$ & 5 & 9 & 1.24 & 1.16 \\
\hline $\mathrm{Fe}$ & & $\mathrm{GeV} \mathrm{p}$ & $\mathrm{A}$ & 4 & 38 & 1.11 & 1.01 \\
\hline Co & 590 & $\mathrm{MeV} p$ & $\mathrm{~K}$ & 5 & 37 & 1.12 & 1.23 \\
\hline Co & 600 & $\mathrm{MeV} p$ & A & 4 & 38 & 1.07 & 1.04 \\
\hline Co & 18 & $\mathrm{GeV} \mathrm{p}$ & $\mathrm{K}$ & 5 & 37 & 1.10 & 1.16 \\
\hline $\mathrm{Ni}$ & 590 & $\mathrm{MeV}$ p & K & 5 & 37 & 1.25 & 1.16 \\
\hline $\mathrm{Ni}$ & 600 & $\mathrm{MeV} \mathrm{p}$ & A & 6 & 38 & 1.26 & 1.09 \\
\hline $\mathrm{Cu}$ & 340 & $\mathrm{MeV} \mathrm{p}$ & Mn & 4 & 13 & 1.09 & 1.17 \\
\hline $\mathrm{Cu}$ & 340 & $\mathrm{MeV} p$ & $\mathrm{Fe}$ & 4 & 13 & 1.11 & 1.25 \\
\hline $\mathrm{Cu}$ & 600 & $\mathrm{MeV} \mathrm{p}$ & A & 7 & 38 & 1.38 & 1.19 \\
\hline $\mathrm{Cu}$ & 680 & $\mathrm{MeV} \mathrm{p}$ & Co & 4 & 16 & 1.05 & 1.02 \\
\hline $\mathrm{Cu}$ & 980 & $\mathrm{MeV} p$ & $\mathrm{~K}$ & 4 & 17 & 1.43 & 1.51 \\
\hline $\mathrm{Cu}$ & & $\mathrm{GeV} \mathrm{p}$ & $\mathrm{Mn}$ & 4 & 18 & 1.11 & 1.20 \\
\hline $\mathrm{Cu}$ & 2. & $\mathrm{GeV} \mathrm{p}$ & $\mathrm{Fe}$ & 4 & 18 & 1.03 & 1.10 \\
\hline $\mathrm{Cu}$ & 3. & $\mathrm{GeV} p$ & Co & 5 & 19 & 1.07 & 1.19 \\
\hline $\mathrm{Cu}$ & 5. & $\mathrm{GeV} \mathrm{p}$ & $\mathrm{Sc}$ & 4 & 20 & 1.02 & 1.10 \\
\hline $\mathrm{Cu}$ & 5. & $\mathrm{GeV} \mathrm{p}$ & Mn & 4 & 20 & 1.04 & 1.03 \\
\hline $\mathrm{Cu}$ & 5. & $\mathrm{GeV}$ p & $\mathrm{Fe}$ & 4 & 20 & 1.01 & 1.15 \\
\hline $\mathrm{Cu}$ & 5. & $\mathrm{GeV} \mathrm{p}$ & Co & 6 & 20 & 1.20 & 1.17 \\
\hline $\mathrm{Cu}$ & 18 & $\mathrm{GeV} \mathrm{p}$ & $\mathrm{K}$ & 5 & 37 & 1.18 & 1.16 \\
\hline $\mathrm{Cu}$ & 20 & $\mathrm{GeV} \mathrm{p}$ & Co & 5 & 19 & 1.16 & 1.30 \\
\hline $\mathrm{Cu}$ & 24 & $\mathrm{GeV} \mathrm{p}$ & Sc & 5 & 21 & 1.12 & 1.12 \\
\hline $\mathrm{Cu}$ & 24 & $\mathrm{GeV} \mathrm{p}$ & Mn & 4 & 21 & 1.47 & 1.66 \\
\hline $\mathrm{Cu}$ & 24 & $\mathrm{GeV} \mathrm{p}$ & Co & 5 & 21 & 1.41 & 1.50 \\
\hline $\mathrm{Cu}$ & 25 & $\mathrm{GeV} \mathrm{p}$ & A & 4 & 38 & 1.10 & 1.00 \\
\hline $\mathrm{Cu}$ & 30 & $\mathrm{GeV} \mathrm{p}$ & Co & 5 & 19 & 1.16 & 1.29 \\
\hline As & 49 & $\mathrm{MeV} p$ & $\mathrm{Ga}$ & 5 & 1 & 1.28 & 1.18 \\
\hline As & 103 & $\mathrm{MeV} \mathrm{p}$ & $\mathrm{Ga}$ & 6 & 1 & 1.36 & 1.26 \\
\hline As & 103 & $\mathrm{MeV} \mathrm{p}$ & $\mathrm{Ge}$ & 4 & 1 & 1.05 & 1.13 \\
\hline As & 170 & $\mathrm{MeV} \mathrm{p}$ & $\mathrm{Cu}$ & 4 & 1 & 1.02 & 1.17 \\
\hline As & 170 & $\mathrm{MeV} p$ & $\mathrm{Ga}$ & 6 & 1 & 1.33 & 1.31 \\
\hline As & 170 & $\mathrm{MeV} \mathrm{p}$ & $\mathrm{Ge}$ & 4 & 1 & 1.21 & 1.31 \\
\hline As & 190 & $\mathrm{MeV} \mathrm{d}$ & $\mathrm{Cu}$ & 4 & 23 & 1.04 & 1.02 \\
\hline As & 380 & $\mathrm{MeV} p$ & Mn & 4 & 24 & 1.27 & 1.70 \\
\hline As & 380 & $\mathrm{MeV} \mathrm{p}$ & $\mathrm{Fe}$ & 4 & 24 & 1.12 & 1.34 \\
\hline $\mathrm{As}$ & 380 & $\mathrm{MeV} p$ & Co & 5 & 24 & 1.39 & 1.51 \\
\hline As & 380 & $\mathrm{MeV} \mathrm{p}$ & $\mathrm{Cu}$ & 6 & 24 & 1.30 & 1.42 \\
\hline As & 380 & $\mathrm{MeV} \mathrm{p}$ & $\mathrm{Ga}$ & 6 & 24 & 1.25 & 1.23 \\
\hline As & 590 & $\mathrm{MeV} p$ & $\mathrm{Sc}$ & 5 & 25 & 1.30 & 1.32 \\
\hline As & 590 & $\mathrm{MeV} \mathrm{p}$ & Co & 5 & 25 & 1.32 & 1.46 \\
\hline As & 590 & $\mathrm{MeV} \mathrm{p}$ & $\mathrm{Ga}$ & 4 & 25 & 1.15 & 1.19 \\
\hline As & 590 & $\mathrm{MeV} p$ & $\mathrm{Ge}$ & 4 & 25 & 1.01 & 1.06 \\
\hline As & & $\mathrm{GeV} \mathrm{p}$ & $\mathrm{Ga}$ & 4 & 26 & 1.08 & 1.16 \\
\hline $\mathbf{Y}$ & 240 & $\mathrm{MeV} \mathrm{p}$ & $\mathrm{Ge}$ & 4 & 27 & 2.63 & 2.35 \\
\hline Ag & 340 & $\mathrm{MeV} \mathrm{p}$ & As & 5 & 29 & 1.35 & 1.30 \\
\hline $\mathrm{Ag}$ & 340 & $\mathrm{MeV} \mathrm{p}$ & $\mathrm{Br}$ & 5 & 29 & 1.36 & 1.30 \\
\hline $\mathrm{Ag}$ & 340 & $\mathrm{MeV} \mathrm{p}$ & $\mathrm{Rb}$ & 5 & 29 & 1.12 & 1.09 \\
\hline $\mathrm{Ag}$ & 480 & $\mathrm{MeV} \mathrm{p}$ & As & 4 & 30 & 1.15 & 1.19 \\
\hline In & 2. & $\mathrm{GeV} \mathrm{p}$ & $\mathrm{Ga}$ & 4 & 31 & 1.07 & 1.03 \\
\hline $\mathrm{Sb}$ & 190 & $\mathrm{MeV} \mathrm{d}$ & $\mathrm{Ru}$ & 4 & 32 & & 1.64 \\
\hline $\mathrm{Sb}$ & 190 & $\mathrm{MeV} d$ & $\mathrm{Pd}$ & 5 & 32 & 2.37 & 2.35 \\
\hline $\mathrm{Sb}$ & 190 & $\mathrm{MeV} \mathrm{d}$ & $\mathrm{Ag}$ & 4 & 32 & 1.26 & 1.13 \\
\hline $\mathrm{Sb}$ & 380 & $\mathrm{MeV} \propto$ & $\mathrm{Pd}$ & 5 & 32 & 1.41 & 1.23 \\
\hline $\mathrm{Sb}$ & 380 & $\mathrm{MeV} \alpha$ & $\mathrm{Ag}$ & 4 & 32 & 1.11 & 1.15 \\
\hline $\mathrm{Cs}$ & 100 & $\mathrm{MeV} \mathrm{p}$ & I & 4 & 33 & 1.25 & 1.06 \\
\hline Cs & 590 & $\mathrm{MeV} p$ & I & 9 & 39 & 1.23 & 1.25 \\
\hline La & 590 & $\mathrm{MeV} \mathrm{p}$ & $\mathrm{I}$ & 14 & 39 & 1.21 & 1.33 \\
\hline $\mathrm{La}$ & 18 & $\mathrm{GeV} \mathrm{p}$ & I & 14 & 39 & 1.31 & 1.29 \\
\hline $\mathrm{Nd}$ & 590 & $\mathrm{MeV} p$ & I & 6 & 39 & 1.15 & 1.32 \\
\hline $\mathrm{Sm}$ & 590 & $\mathrm{MeV} p$ & I & 6 & 39 & 1.14 & 1.21 \\
\hline
\end{tabular}

Table 2. 


\begin{tabular}{|c|c|c|c|c|c|c|c|}
\hline \multirow{2}{*}{ Target } & \multirow{2}{*}{\multicolumn{2}{|c|}{ Irradiation }} & \multirow{2}{*}{ Element studied } & \multirow{2}{*}{$\begin{array}{l}\text { No of exp. } \\
\text { results }\end{array}$} & \multirow{2}{*}{ Reference } & \multicolumn{2}{|c|}{$e^{\varepsilon}$} \\
\hline & & & & & & ICSD-G & ICSD \\
\hline $\mathrm{Ta}$ & 18 & $\mathrm{GeV} \mathrm{p}$ & $\mathrm{I}$ & 7 & 39 & 1.90 & 1.68 \\
\hline $\mathrm{Au}$ & 18 & $\mathrm{GeV} \mathrm{p}$ & $\mathrm{I}$ & 6 & 39 & 1.24 & 1.28 \\
\hline $\mathrm{Bi}$ & 380 & $\mathrm{MeV} \mathrm{p}$ & $\mathrm{Au}$ & 5 & 34 & 1.73 & 1.46 \\
\hline $\mathrm{Bi}$ & 660 & $\mathrm{MeV} \mathrm{p}$ & $\mathrm{Au}$ & 4 & 35,36 & 1.64 & 1.73 \\
\hline $\mathrm{Bi}$ & 660 & $\mathrm{MeV} \mathrm{p}$ & $\mathrm{Bi}$ & 6 & 35,36 & 1.16 & 1.15 \\
\hline $\mathrm{Th}$ & 150 & $\mathrm{MeV} \mathrm{p}$ & $\mathrm{Th}$ & 4 & 40 & 1.68 & 1.47 \\
\hline $\mathrm{Th}$ & 155 & $\mathrm{MeV} \mathrm{p}$ & Po & 5 & 41 & 1.64 & 1.53 \\
\hline $\mathrm{Th}$ & 155 & $\mathrm{MeV} p$ & At & 5 & 41 & 1.04 & 1.06 \\
\hline $\mathrm{U}$ & 340 & $\mathrm{MeV} p$ & $\mathrm{Ra}$ & 4 & 42 & 1.19 & 1.15 \\
\hline $\mathrm{U}$ & 340 & $\mathrm{MeV} p$ & Th & 5 & 42 & 1.07 & 1.05 \\
\hline $\mathrm{U}$ & 340 & $\mathrm{MeV} \mathrm{p}$ & $\mathrm{Pa}$ & 5 & 42 & 1.12 & 1.05 \\
\hline $\mathrm{U}$ & 660 & $\mathrm{MeV} \mathrm{p}$ & $\mathrm{Bi}$ & 5 & 43 & 1.20 & 1.24 \\
\hline $\mathrm{U}$ & 680 & $\mathrm{MeV} \mathrm{p}$ & $\mathrm{Pa}$ & 7 & 44 & 1.47 & 1.50 \\
\hline $\mathrm{U}$ & & $\mathrm{GeV} \mathrm{p}$ & $\mathrm{Pa}$ & 7 & 44 & 1.43 & 1.44 \\
\hline
\end{tabular}

Table 2. Spallation data used for fitting ICSD-G and ICSD-distributions.

\section{Systematic behaviour of the parameters of the cross-section formulas}

\subsection{The parameter $P$}

The parameter $P$ corresponding to the CDMD distribution has been plotted versus irradiation energy for spallation of medium-weight elements $\left(Z_{\mathrm{t}}=23-47\right)$ in Fig. 1. The parameter first decreases rapidly with increasing irradiation energy and then approaches a constant value. The experi-

7 C.G. Heininger and E. O.Wiig, Phys. Rev. 101, 1074 [1956].

8 G. Rudstam, P. C. Stevenson, and R. L. Folger, Phys. Rev. 87, 358 [1952].

9 P. Estrup, Geochim. Cosmochim. Acta 27, 891 [1963].

10 E. Belmont, Phys. Rev. 95, 1554 [1954].

11 G. Carleson, Acta Chem. Scand. 8, 1697 [1954].

12 C. H. Coleman and H. A. Tewes, Phys. Rev. 99, 288 [1955].

13 R. E. Batzel, D. R. Miller, and G. T. Seaborg, Phys. Rev. 84, 671 [1951].

14 L. Marquez, Phys. Rev. 88, 225 [1952].

15 A. N. Murin, B. K. Preobrazhenskit, I. A. Yutlandov, and M. A.Y cal Sciences. Session of the Academy of Sciences of the USSR on the Peaceful Use of Atomic Energy, July 1-5, 1955, Moskva 1955.

16 A. P. Vinogradov, I. P. Alimarin, V. I. Baranov, A. K. Lavrukhina, T. V. Baranova, and F. I. Pavlotskaya, p. 132 of Ref. ${ }^{15}$.

17 P. Reasbeck and J. E. W 343 [1958].

18 G. Friedlander, J. M. Miller, R. Wolfgang, J. Hudis, and E. BAKER, Phys. Rev. 94, 727 [1954].

19 J. Hudis, I. Dostrovsky, G. Friedlander, J. R. Grover, N. T. Porile, L. P. Remsberg, R. W. Stoenner, and S. Tanaka, Phys. Rev. 129, 434 [1963].

20 D. W. BARR, University of California Radiation Laboratory Report UCRL-3793 [1957].

21 G. Rudstam, E. Bruninx, and A. C. Pappas, Phys. Rev. 126, 1852 [1962].

22 W. J. Worthington, University of California Radiation Laboratory Report UCRL-1627 [1952].

23 H. H. Hopkins, Jr., Phys. Rev. 77, 717 [1950].

24 J. B. Cumming, American Report NYO-6141 [1954]. mental data are well represented by the two straight lines indicated in the figure, one for the descending part and another one for the constant part. This means that one can approximate $P$ by the function

$$
\begin{aligned}
& P=a^{\prime} E^{-b^{\prime}} \text { for } E<E_{0}, \\
& P=c^{\prime} \quad \text { for } E>E_{0}
\end{aligned}
$$

where $E$ is the irradiation energy in $\mathrm{MeV}$ and $a^{\prime}, b^{\prime}$, and $c^{\prime}$ are positive constants. For CDMD-G, IDED, and IDED-G similar results are obtained. The values found for the constants are given in Table 3 .

25 G. Rudstam and E. Bruninx, J. Inorg. Nucl. Chem. 23, 161 [1961].

26 S. B. Kaufman, Phys. Rev. 126, 1189 [1962].

27 A. A. Caretto, Jr., and E. O. Wirg, Phys. Rev. 103, 236 [1956].

28 R. G. Konteling and E. K. Hyde, University of California Lawrence Radiation Laboratory Report UCRL-11391 [1964].

29 P. K. Kofstad, University of California Radiation Laboratory Report UCRL-2265 [1953].

30 B. V. Kurchatov, V. N. Mekhedov, N. I. Borisova, M. Ya. Kuznetsova, L. N. Kurchatova, and L. V. Christyakev, p. 178 of Ref. ${ }^{15}$

31 S. B. Kaufman, Phys. Rev. 129, 1866 [1963].

32 M. Lindner and I. Perlman, Phys. Rev. 78, 499 [1950].

33 R. W. Fink and E. O. WIIG, Phys. Rev. 94, 1357 [1954].

34 E. T. Hunter and J. M. Miller, Phys. Rev. 115, 1053 [1959].

35 A. V. Kaliamin, A. N. Murin, B. K. Preobrazhenseir, and N. E. Titov, J. Nucl. Energy 9, 165 [1959].

36 T. V. Malysheva and I. P. Alimarin, Soviet Phys. JETP 35, 772 [1959].

37 K. F. Chackett, J. Inorg. Nucl. Chem. 27, 2493 [1965].

38 K. Goebel, H. Schultes, and J. Zähringer, CERN Report 64-12 [1964].

39 G. Rudstam and G. Sörensen, J. Inorg. Nucl. Chem. 28, 771 [1966].

40 M. Lefort, G. N. Simonoff, and X. Tarrago, Nucl. Phys. 25, 216 [1961]

41 X. Tarrago, J. Phys. Rad. 23, 1 [1962].

42 M. Lindner and R. Osborne, Phys. Rev. 103, 378 [1956].

43 A. K. Lavrukhina and S. Rodin, Radiokhimiya 2, 83 [1960].

44 B.D.Pate and A.M. Poskanzer, Phys. Rev. 123, 647 [1961]. 


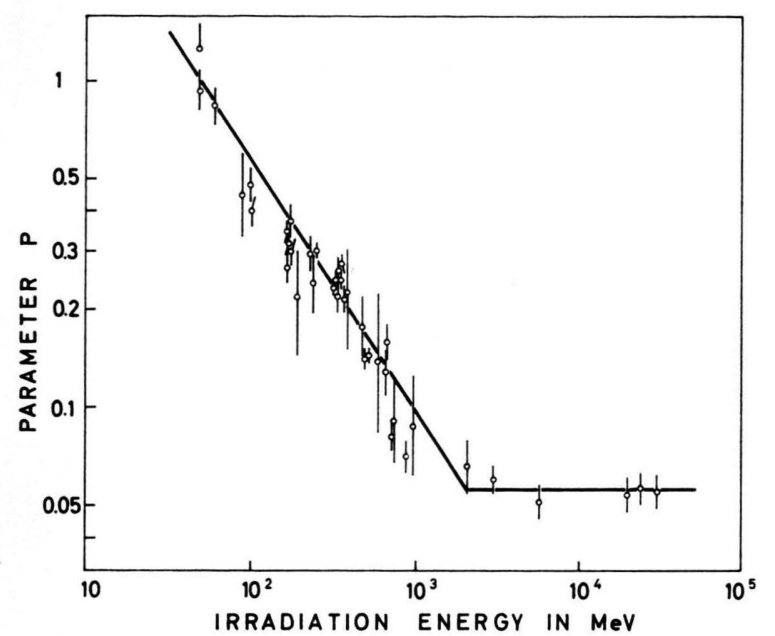

Fig. 1. Parameter $P$ versus the irradiation energy for the CDMD distribution. The solid line is $P$ defined by Eq. (15) with constants from Table 3 .

The parameter $P$ does not depend on the kind of projectile used. Protons, neutrons, deuterons, and alpha particles give the same value. As an example some results from proton and alpha-particle irradiation of niobium ${ }^{28}$ are compared in Table 4.

For the average mass number of the spallation products one finds the expression:

CDMD-G and CDMD:

$\bar{A}=\frac{\sum A \sigma(Z, A)}{\sum \sigma(Z, A)} \sim \frac{\int_{0}^{A_{\mathrm{t}}} A e^{P A} \mathrm{~d} A}{\int_{0}^{A_{\mathrm{t}}} e^{P A} \mathrm{~d} A}=\frac{e^{P A_{\mathrm{t}}\left(P A_{\mathrm{t}}-1\right)+1}}{P\left(e^{\left.P A_{\mathrm{t}}-1\right)}\right.}$

$\sim A_{\mathrm{t}}-\frac{1}{P}$.
Likewise, one finds for the average atomic number from IDED-G and IDED:

$$
\bar{Z} \sim Z_{\mathrm{t}}-\frac{1}{P} .
$$

Thus the average number of emitted nucleons (free or bound) is obtained as

$$
\begin{aligned}
& \overline{\Delta A}=A_{\mathrm{t}}-\bar{A} \sim \frac{1}{P_{\mathrm{C}}} ; \\
& \overline{\Delta Z}=Z_{\mathrm{t}}-\bar{Z} \sim \frac{1}{P_{\mathrm{I}}} .
\end{aligned}
$$

Notation: $P_{\mathrm{C}}$ for $\operatorname{CDMD}(-\mathrm{G})$ and $P_{\mathrm{I}}$ for $\operatorname{IDED}(-\mathrm{G})$.

To these numbers should be added about one unit taking into account that the incoming particle (here assumed to be a proton) is very often re-emitted.

The parameter $P$ is closely related to the first part of the spallation reaction, i. e. the nucleonic cascade. Monte-Carlo calculations ${ }^{45}$ indicate an increase of the excitation energy for increasing mass number of the target, the irradiation energy being kept constant. This would mean an increase in the number of evaporated nucleons which is roughly proportional to the excitation energy (the number of cascade particles seems to depend rather little on the kind of target used). According to the relation (18) the parameter $P_{\mathrm{C}}$ should then decrease with increasing mass of the target. For protons the situation is somewhat more complicated. The increase in excitation energy is counteracted by the increasing potential barrier so that the number of evaporated protons might be very little influenced. Unfortunately the number of spallation investigations in the heavy element region is small, and the variation of $P$ with

\begin{tabular}{|c|c|c|c|c|}
\hline & CDMD-G & CDMD & IDED-G & IDED \\
\hline$E_{0}(\mathrm{MeV})$ & 2900 & 2100 & 3050 & 2400 \\
$a^{\prime}$ & $13 \pm 4$ & $20 \pm 7$ & $21 \pm 7$ & $30 \pm 11$ \\
$b^{\prime}$ & $0.69 \pm 0.05$ & $0.77 \pm 0.06$ & $0.64 \pm 0.05$ & $0.70 \pm 0.06$ \\
$c^{\prime}$ & $0.054 \pm 0.002$ & $0.056 \pm 0.003$ & $0.124 \pm 0.005$ & $0.129 \pm 0.005$ \\
\hline
\end{tabular}

Table 3. Constants defining the variation of the parameter $P$ with irradiation energy. $Z_{\mathrm{t}}=23-47$.

\begin{tabular}{|c|c|c|c|c|}
\hline \multirow{2}{*}{$\begin{array}{c}\text { Irradiation } \\
\text { energy }\end{array}$} & \multicolumn{2}{|c|}{ Parameter $P$} & \multicolumn{2}{c|}{ Parameter $R$} \\
\cline { 2 - 3 } \cline { 4 - 5 } & Protons & Alpha-particles & Protons & Alpha-particles \\
\hline $240 \mathrm{MeV}$ & $0.303 \pm 0.011$ & & $1.64 \pm 0.13$ & \\
$320 \mathrm{MeV}$ & $0.233 \pm 0.011$ & $0.246 \pm 0.011$ & $1.73 \pm 0.12$ & $1.51 \pm 0.13$ \\
$500 \mathrm{MeV}$ & $0.142 \pm 0.008$ & $0.145 \pm 0.006$ & $1.75 \pm 0.09$ & $1.68 \pm 0.07$ \\
$720 \mathrm{MeV}$ & $0.081 \pm 0.008$ & $0.091 \pm 0.028$ & $1.83 \pm 0.09$ & $1.66 \pm 0.29$ \\
$880 \mathrm{MeV}$ & & $0.071 \pm 0.007$ & & $1.71 \pm 0.07$ \\
\hline
\end{tabular}

Table 4. Comparison of CDMD distributions for proton and alpha-particle induced spallation of niobium.

45 N. Metropolis, R. Bivins, M. Storm, A. Turkevich, J. M. Miller, and G. Friedlander, Phys. Rev. 110,185 [1958]. 
kind of target is not established. Some bismuth results indicate, however, a change of $P_{\mathrm{C}}$ in the expected direction as shown in Table 5.

\begin{tabular}{|l|c|c|}
\hline \multirow{2}{*}{ Energy interval } & \multicolumn{2}{|c|}{ Parameter $P$} \\
\cline { 2 - 3 } & $\begin{array}{c}\text { Average for } \\
Z_{\mathrm{t}}=23-47\end{array}$ & $Z_{\mathrm{t}}=83$ \\
\hline $370-400 \mathrm{MeV}$ & $0.226 \pm 0.011$ & $0.097 \pm 0.011$ \\
$480-500 \mathrm{MeV}$ & $0.144 \pm 0.004$ & $0.105 \pm 0.029$ \\
$660-680 \mathrm{MeV}$ & $0.145 \pm 0.015$ & $0.079 \pm 0.007$ \\
\hline
\end{tabular}

Table 5. Target dependence of the parameter $P$ for CDMD distributions.

An interesting comparison can be made between the $P_{\mathrm{I}}$ values obtained in the present treatment and the distribution of stars in emulsion experiments. WINZELER ${ }^{46}$ has shown that the frequency of stars of a certain size varies roughly exponentially with the number of prongs in the star. For irradiations with $22.5 \mathrm{GeV}$ protons he found the average number of gray and black prongs (mesons subtracted) to be $8.60 \pm 0.25$. From $P_{\mathrm{I}}=0.127$ (Table 3 ) $\overline{\Delta Z}$ is obtained as 7.9. If it is assumed that, in addition, one proton always leaves the target nucleus (at these energies the probability of making products of atomic number higher than that of the target is negligible ${ }^{47}$, the average number of emitted protons comes out to be 8.9. This is in good agreement with the number 10.3 resulting from multiplying the average number of prongs with the average charge per prong which is about $1.2^{46}$. It must be remembered, however, that the emulsion results contain contributions both from light emulsion nuclei and from silver bromide.

\subsection{The parameter $R$}

The parameter $R$ is found to be independent of the kind and energy of the projectiles as exemplified in Table 4. On the other hand, $R$ depends on the mass number (atomic number) of the spallation product. This is shown in Fig. 2 (for the CDMD

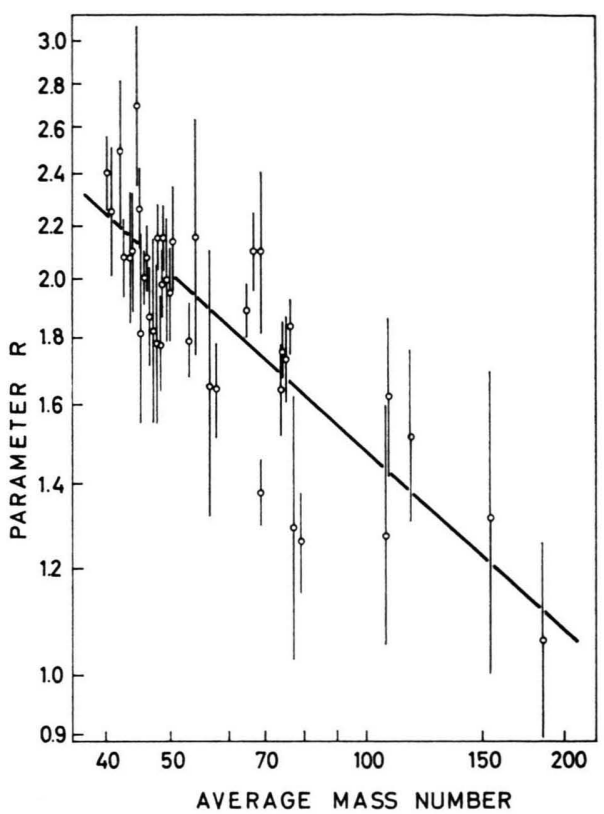

Fig. 2. Parameter $R$ versus the mass number of the spallation product for the CDMD distribution. The solid line is $R$ defined by Eq. (19) with constants from Table 6.

distribution) where $R$ has been plotted on a log-log scale versus the average mass number of the reaction product. The $R$-values are reasonably well represented by a function of the type

$$
R=d^{\prime} A^{-e^{\prime}} \text { for CDMD and CDMD-G }
$$

and

$$
R=d^{\prime} Z^{-e^{\prime}} \text { for IDED and IDED-G. }
$$

The best values of the constants $d^{\prime}$ and $e^{\prime}$ are given in Table 6.

It seems probable that the final shape of the charge distribution (isotopic distribution) is mainly determined by the evaporation part of the spallation. The memory of how the excited nucleus was formed is then almost lost which explains why $R$ is independent of the kind and energy of the bombarding particles. Important quantities in the evaporation step are,

\begin{tabular}{|c|c|c|c|c|}
\hline & CDMD-G & CDMD & IDED-G & IDED \\
\hline$d^{\prime}$ & $17.4 \pm 4.4$ & $11.8 \pm 3.0$ & $4.09 \pm 1.07$ & $9.3 \pm 1.4$ \\
$e^{\prime}$ & $0.64 \pm 0.07$ & $0.45 \pm 0.07$ & $0.91 \pm 0.11$ & $0.89 \pm 0.04$ \\
\hline
\end{tabular}

Table 6. Constants defining the variation of the parameter $R$ with the mass number or atomic number of the spallation product. 
however, the separation energies of neutrons and protons. If the separation energies vary rapidly from isobar to isobar the charge distribution will be narrow, i. e. $R$ should be large. This is the case in the medium-weight region. In the heavy mass region this variation is less rapid, and hence $R$ should be smaller. Similar arguments hold for the isotopic distributions. Thus the decrease of the parameter $R$ is in qualitative agreement with the widening of the mass valley.

\subsection{The parameters $S$ and $T$}

The parameters $S$ and $T$ define the position of the peak of the charge distribution (isotopic distribution). For the same reasons as in the case of the parameter $R$, this position should be independent of the irradiation conditions and only depend on the proton and neutron separation energies and on the Coulomb barrier. This independence of irradiation conditions is exemplified in Table 7 for the yield distribution of cobalt isotopes.

\begin{tabular}{|c|c|c|}
\hline Target & Irradiation & Peak position \\
\hline $\mathrm{Cu}$ & $680 \mathrm{MeV} \mathrm{p}$ & $58.78 \pm 0.04$ \\
$\mathrm{Cu}$ & $3.0 \mathrm{GeV} \mathrm{p}$ & $58.50 \pm 0.14$ \\
$\mathrm{Cu}$ & $5.7 \mathrm{GeV} \mathrm{p}$ & $58.40 \pm 0.10$ \\
$\mathrm{Cu}$ & $20 \mathrm{GeV} \mathrm{p}$ & $57.75 \pm 0.22$ \\
$\mathrm{Cu}$ & $24 \mathrm{GeV} \mathrm{p}$ & $58.50 \pm 0.46$ \\
$\mathrm{Cu}$ & $30 \mathrm{GeV} \mathrm{p}$ & $58.49 \pm 0.22$ \\
$\mathrm{As}$ & $380 \mathrm{MeV} \mathrm{p}$ & $58.83 \pm 0.43$ \\
$\mathrm{As}$ & $590 \mathrm{MeV} \mathrm{p}$ & $58.44 \pm 0.21$ \\
\hline
\end{tabular}

Table 7. Peak position of the distribution of cobalt isotopes for different targets and irradiation energies (ICSD distributions).

In Fig. 3 the ratio between the most probable mass number $A_{\mathrm{p}}$ of the isotopic distribution (ICSD distributions) and the atomic number has been plotted as a function of the atomic number. The points fall well on a straight line which shows that the form

$$
A_{\mathrm{p}}=S Z+T Z^{2}
$$

is a good approximation. Only for heavy elements the experimental points deviate from this line falling above. This can be interpreted as a result of competition between neutron evaporation and fission. The cross-section of spallation products far from stability is decreased because too many neutrons have to be evaporated to form such products, giving fission a good chance to compete. Thus Eq. (21) and the corresponding form of $Z_{\mathrm{p}}$ [Eq. (2)] should be

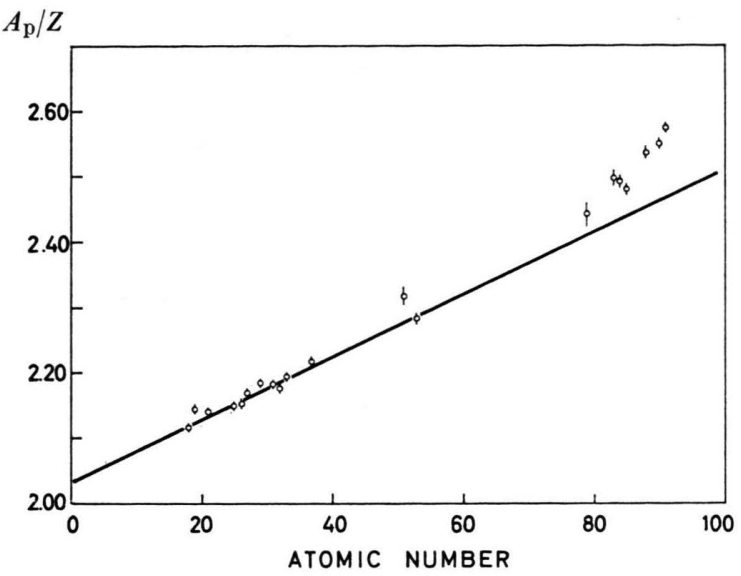

Fig. 3. Ratio between the position of the peak of the isotopic distribution and the atomic number plotted as a function of the atomic number (ICSD distribution). The straight line has been determined with the least squares method including data up to $Z=53$.

used only for elements with low fissionability $(Z<75 ; A<185)$.

The values of $S$ and $T$ derived from $\operatorname{ICSD}(-G)$ distributions for $Z \leqq 53$ and from $\operatorname{IDED}(-G)$ and CDMD (-G) distributions corresponding to target elements of atomic number $\leqq 47$ are given in Table 8. As expected there is no significant difference between the $A_{\mathrm{p}}$ values obtained from $\operatorname{ICSD}(-\mathrm{G})$ and $\operatorname{IDED}(-\mathrm{G})$, nor between $Z_{\mathrm{p}}$ values obtained from CDMD and CDMD-G.

\begin{tabular}{|l|l|l|}
\hline Distribution & Parameter $S$ & Parameter $T$ \\
\hline CDMD-G & $0.487 \pm 0.001$ & $0.00041 \pm 0.00003$ \\
CDMD & $0.486 \pm 0.001$ & $0.00038 \pm 0.00002$ \\
IDED-G & $2.069 \pm 0.007$ & $0.0036 \pm 0.0002$ \\
IDED & $2.080 \pm 0.007$ & $0.0032 \pm 0.0002$ \\
ICSD-G & $2.049 \pm 0.012$ & $0.0043 \pm 0.0004$ \\
ICSD & $2.034 \pm 0.007$ & $0.0048 \pm 0.0002$ \\
\hline
\end{tabular}

Table 8. Values of the parameters $S$ and $T$ for different kinds of distributions.

\subsection{The parameter $\hat{\sigma}$}

From the definition of the parameter $\hat{\sigma}$ it is evident that it should be roughly equal to the total inelastic cross-section. The scattering of the $\hat{\sigma}$ values is large, however, and a detailed comparison is hardly worth while especially since the definition of $\hat{\sigma}$ will be somewhat changed in section 4.1. At the present stage it is sufficient to note that (i) the copper results do not indicate any significant energy-dependence of $\hat{\sigma}$ in the energy range $190 \mathrm{MeV}-30 \mathrm{GeV}$, in accordance with findings for the inelastic cross- 
section ${ }^{48}$, and (ii) that $\hat{\sigma}$ increases with increasing target mass in roughly the same way as does the inelastic cross-section ${ }^{49}$.

The copper results might serve as an example of the agreement between $\hat{\sigma}$ and the inelastic cross-section. As an average of all determinations with copper targets $\hat{\sigma}$ is obtained as $(810 \pm 40) \mathrm{mb}$ using the CDMD distribution, the other distributions yielding similar values. This should be compared to the total inelastic cross-section $710 \mathrm{mb}$ determined by Asнmore et al. ${ }^{49}$.

\section{Comparison between the different cross- section formulas}

\subsection{Estimation of spallation cross-sections}

Using Eqs. (4) to (7) and the parameters from section 3 , it is now possible to estimate spallation cross-sections. As indicated in section 1.1 the constant appearing in these equations can be related to the inelastic cross-section. However, this was earlier done [Eqs. (10) $\mathrm{ff}$ ] assuming the parameter $R$ to be independent of the mass number (atomic number) of the spallation product. Fig. 2 clearly shows that this is not the case, and the treatment of this point therefore has to be modified. For CDMD-G distributions one can start from Eq. (10). Using for $R$ the expression Eq. (19) one obtains

$$
\sigma_{i} \sim \text { const } \times \frac{\pi^{1 / 2}}{d^{1 / 2}} \int_{0}^{A_{\mathrm{t}}} A^{1 / 2} e^{\prime} e^{P A} \mathrm{~d} A \sim \text { const } \times \frac{\pi^{1 / 2} A_{\mathrm{t}}^{1 / 2} e^{\prime}\left[e^{\left.P A_{\mathrm{t}}\left(1-\frac{e^{\prime}}{2 P A_{\mathrm{t}}}\right)-1+1 / 2 e^{\prime}+\frac{e^{\prime}}{2 P A_{\mathrm{t}}}\right]}\right.}{P d^{1 / 2}} .
$$

Now the parameter $\hat{\sigma}$ is introduced by the relation

and we have as before $\hat{\sigma} \sim \sigma_{i}$

$$
\text { const }=\frac{\hat{\sigma} P d^{1 / 2} A_{\mathrm{t}}{ }^{-1 / 2 e^{\prime}}}{\pi^{1 / 2}\left[e^{P A_{\mathrm{t}}}\left(1-\frac{e^{\prime}}{2 P A_{\mathrm{t}}}\right)-1+1 / 2 e^{\prime}+\frac{e^{\prime}}{2 P A_{\mathrm{t}}}\right]}
$$

For the other distributions the constants are approximated in a similar manner, and the final cross-section formulas become as follows:

$$
\begin{aligned}
& \text { CDMD-G: } \sigma(Z, A)=\frac{\hat{\sigma} P d^{n / 2} A_{\mathrm{t}}^{-1 / 2} e^{\prime}}{\pi^{1 / 2}\left[e^{P A_{\mathrm{t}}}\left(1-\frac{e^{\prime}}{2 P A_{\mathrm{t}}}\right)-1+1 / 2 e^{\prime}+\frac{e^{\prime}}{2 P A_{\mathrm{t}}}\right]^{-2}} \times \exp \left[P A-R\left(Z-S A+T A^{2}\right)^{2}\right] \\
& \text { CDMD: } \sigma(Z, A)=\frac{\hat{\sigma} P d^{\prime 2 / s} A_{\mathrm{t}}-2 / s e^{\prime}}{1.79\left[e^{P A_{\mathrm{t}}}\left(1-\frac{2 e^{\prime}}{3 P A_{\mathrm{t}}}\right)-1+\frac{2 e^{\prime}}{3}+\frac{2 e^{\prime}}{3 P A_{\mathrm{t}}}\right]} \times \exp \left[P A-R\left|Z-S A+T A^{2}\right|^{3 / 2}\right] \\
& \text { IDED-G: } \sigma(Z, A)=\frac{\hat{\sigma} P d^{1 / 2} Z_{\mathrm{t}}-1 / 2 e^{\prime}}{\left.\pi^{1 / 2}\left[e^{P Z_{\mathrm{t}}\left(1-\frac{e^{\prime}}{2 P Z_{\mathrm{t}}}\right)}\right)-1+1 / 2 e^{\prime}+\frac{e^{\prime}}{2 P Z_{\mathrm{t}}}\right]} \times \exp \left[P Z-R\left(A-S Z-T Z^{2}\right)^{2}\right] \\
& \text { IDED : } \sigma(Z, A)=\frac{\hat{\sigma} P d^{\prime 2 / 3} Z_{\mathrm{t}}-2 / s e^{\prime}}{1.79\left[e^{P Z_{\mathrm{t}}\left(1-\frac{2 e^{\prime}}{3 P Z_{\mathrm{t}}}\right)}-1+\frac{2 e^{\prime}}{3}+\frac{2 e^{\prime}}{3 P Z_{\mathrm{t}}}\right]} \times \exp \left[P Z-R\left|A-S Z-T Z^{2}\right|^{3 / 2}\right] \text {. }
\end{aligned}
$$

48 J. H. Atrinson, W. N. Hess, V. Perez-Mendez, and R. WaLLACE, Phys. Rev. 123, 1850 [1961].
49 A. Ashmore, G. Cocconi, A. N. Diddens, and A. M. WetherELL, Phys. Rev. Letters 5, 576 [1960]. 


\begin{tabular}{|c|c|c|c|c|c|c|c|c|}
\hline \multirow{2}{*}{ Target } & \multirow{2}{*}{\multicolumn{2}{|c|}{ Irradiation }} & \multirow{2}{*}{$\begin{array}{l}\text { No. of } \\
\text { exp. } \\
\text { results }\end{array}$} & \multirow{2}{*}{$\begin{array}{l}\text { Refer- } \\
\text { ence }\end{array}$} & \multicolumn{4}{|c|}{ Average ratio $\sigma \exp / \sigma_{\text {calc }}$} \\
\hline & & & & & CDMD-G & CDMD & IDED-G & IDED \\
\hline $\mathrm{Al}$ & & $\mathrm{GeV} p$ & 5 & 50 & $0.53 \pm 0.05$ & $0.61 \pm 0.06$ & $0.52 \pm 0.04$ & $0.57 \pm 0.09$ \\
\hline V & 60 & $\mathrm{MeV} \mathrm{p}$ & 12 & 7 & $0.92 \pm 0.25$ & $1.58 \pm 0.43$ & $0.16 \pm 0.05$ & $0.21 \pm 0.09$ \\
\hline V & 100 & $\mathrm{MeV} p$ & 13 & 7 & $1.45 \pm 0.37$ & $2.02 \pm 0.61$ & $0.84 \pm 0.36$ & $1.22 \pm 0.62$ \\
\hline V & 170 & $\mathrm{MeV} \mathrm{p}$ & 22 & 1 & $1.32 \pm 0.23$ & $1.65 \pm 0.32$ & $0.87 \pm 0.23$ & $1.27 \pm 0.41$ \\
\hline V & 175 & $\mathrm{MeV}$ p & 15 & 7 & $0.48 \pm 0.11$ & $0.58 \pm 0.13$ & $0.23 \pm 0.08$ & $0.28 \pm 0.12$ \\
\hline V & 240 & $\mathrm{MeV} p$ & 16 & 7 & $0.55 \pm 0.16$ & $0.67 \pm 0.19$ & $0.33 \pm 0.14$ & $0.40 \pm 0.20$ \\
\hline V & 590 & $\mathrm{MeV} \mathrm{p}$ & 5 & 37 & $0.57 \pm 0.09$ & $0.75 \pm 0.14$ & $0.56 \pm 0.13$ & $0.83 \pm 0.21$ \\
\hline Mn & 170 & $\mathrm{MeV} \mathrm{p}$ & 18 & 1 & $1.75 \pm 0.24$ & $2.28 \pm 0.35$ & $0.96 \pm 0.22$ & $1.28 \pm 0.38$ \\
\hline $\mathrm{Fe}$ & 130 & $\mathrm{MeV} \mathrm{p}$ & 5 & 51 & $2.03 \pm 0.95$ & $2.18 \pm 1.21$ & $1.33 \pm 0.45$ & $1.47 \pm 0.66$ \\
\hline $\mathrm{Fe}$ & 208 & $\mathrm{MeV} \mathrm{p}$ & 5 & 51 & $1.60 \pm 0.57$ & $1.68 \pm 0.72$ & $1.15 \pm 0.31$ & $1.20 \pm 0.38$ \\
\hline $\mathrm{Fe}$ & 297 & $\mathrm{MeV} \mathrm{p}$ & 5 & 51 & $0.79 \pm 0.26$ & $0.71 \pm 0.27$ & $0.71 \pm 0.19$ & $0.68 \pm 0.22$ \\
\hline $\mathrm{Fe}$ & 340 & $\mathrm{MeV} \mathrm{p}$ & 21 & 8 & $0.57 \pm 0.08$ & $0.64 \pm 0.11$ & $0.58 \pm 0.06$ & $0.71 \pm 0.10$ \\
\hline $\mathrm{Fe}$ & 396 & $\mathrm{MeV} \mathrm{p}$ & 5 & 51 & $0.67 \pm 0.18$ & $0.59 \pm 0.18$ & $0.63 \pm 0.15$ & $0.59 \pm 0.17$ \\
\hline $\mathrm{Fe}$ & 500 & $\mathrm{MeV} \mathrm{p}$ & 6 & 2 & $0.62 \pm 0.06$ & $0.71 \pm 0.10$ & $0.79 \pm 0.09$ & $1.06 \pm 0.24$ \\
\hline $\mathrm{Fe}$ & 590 & $\mathrm{MeV} \mathrm{p}$ & 5 & 37 & $0.70 \pm 0.05$ & $0.82 \pm 0.04$ & $0.96 \pm 0.15$ & $1.33 \pm 0.14$ \\
\hline $\mathrm{Fe}$ & 600 & $\mathrm{MeV} \mathrm{p}$ & 6 & 38 & $1.59 \pm 0.26$ & $1.49 \pm 0.23$ & $1.57 \pm 0.17$ & $1.63 \pm 0.14$ \\
\hline $\mathrm{Fe}$ & 730 & $\mathrm{MeV} \mathrm{p}$ & 17 & 3 & $0.91 \pm 0.13$ & $0.92 \pm 0.13$ & $1.04 \pm 0.14$ & $1.20 \pm 0.19$ \\
\hline $\mathrm{Fe}$ & 24 & $\mathrm{GeV} \mathrm{p}$ & 18 & 9 & $0.58 \pm 0.10$ & $0.66 \pm 0.11$ & $0.61 \pm 0.11$ & $0.70 \pm 0.14$ \\
\hline $\mathrm{Fe}$ & 25 & $\mathrm{GeV} \mathrm{p}$ & 4 & 38 & $1.13 \pm 0.10$ & $1.20 \pm 0.10$ & $1.13 \pm 0.11$ & $1.15 \pm 0.08$ \\
\hline $\mathrm{Fe}$ & 29 & $\mathrm{GeV} \mathrm{p}$ & 4 & 52 & $0.85 \pm 0.16$ & $1.03 \pm 0.15$ & $0.91 \pm 0.20$ & $1.37 \pm 0.34$ \\
\hline Co & 170 & $\mathrm{MeV} p$ & 17 & 1 & $4.04 \pm 0.79$ & $5.36 \pm 1.04$ & $2.05 \pm 0.38$ & $2.61 \pm 0.63$ \\
\hline Co & 370 & $\mathrm{MeV} \mathrm{p}$ & 23 & 10 & $1.26 \pm 0.13$ & $1.22 \pm 0.13$ & $0.96 \pm 0.10$ & $0.96 \pm 0.10$ \\
\hline $\mathrm{Co}$ & 590 & $\mathrm{MeV} \mathrm{p}$ & 5 & 37 & $0.70 \pm 0.07$ & $0.81 \pm 0.08$ & $0.83 \pm 0.16$ & $1.17 \pm 0.20$ \\
\hline Co & 600 & $\mathrm{MeV} \mathrm{p}$ & 4 & 38 & $1.78 \pm 0.21$ & $1.56 \pm 0.13$ & $1.48 \pm 0.22$ & $1.45 \pm 0.11$ \\
\hline $\mathrm{Ni}$ & 130 & $\mathrm{MeV} \mathrm{p}$ & 5 & 51 & $3.13 \pm 1.76$ & $3.53 \pm 2.27$ & $3.85 \pm 1.60$ & $4.85 \pm 2.46$ \\
\hline $\mathrm{Ni}$ & 208 & $\mathrm{MeV} \mathrm{p}$ & 5 & 51 & $1.08 \pm 0.52$ & $1.00 \pm 0.54$ & $1.46 \pm 0.57$ & $1.54 \pm 0.68$ \\
\hline $\mathrm{Ni}$ & 297 & $\mathrm{MeV} \mathrm{p}$ & 5 & 51 & $0.99 \pm 0.46$ & $0.87 \pm 0.46$ & $1.34 \pm 0.52$ & $1.31 \pm 0.58$ \\
\hline $\mathrm{Ni}$ & 396 & $\mathrm{MeV} \mathrm{p}$ & 5 & 51 & $0.72 \pm 0.32$ & $0.62 \pm 0.32$ & $0.96 \pm 0.38$ & $0.90 \pm 0.41$ \\
\hline $\mathrm{Ni}$ & 590 & $\mathrm{MeV} \mathrm{p}$ & 5 & 37 & $0.52 \pm 0.05$ & $0.61 \pm 0.04$ & $0.97 \pm 0.14$ & $1.38 \pm 0.11$ \\
\hline $\mathrm{Ni}$ & 600 & $\mathrm{MeV} \mathrm{p}$ & 6 & 38 & $1.74 \pm 0.52$ & $1.58 \pm 0.46$ & $2.26 \pm 0.52$ & $2.34 \pm 0.42$ \\
\hline $\mathrm{Cu}$ & 90 & $\mathrm{MeV} \mathrm{p}$ & 10 & 12 & $2.16 \pm 0.84$ & $3.75 \pm 1.57$ & $0.38 \pm 0.11$ & $0.44 \pm 0.15$ \\
\hline $\mathrm{Cu}$ & 190 & $\mathrm{MeV}$ p & 11 & 12 & $1.20 \pm 0.37$ & $1.60 \pm 0.47$ & $0.49 \pm 0.11$ & $0.53 \pm 0.13$ \\
\hline $\mathrm{Cu}$ & 400 & $\mathrm{MeV} \mathrm{n}$ & 12 & 14 & $0.66 \pm 0.10$ & $0.80 \pm 0.10$ & $0.46 \pm 0.08$ & $0.47 \pm 0.09$ \\
\hline $\mathrm{Cu}$ & 600 & $\mathrm{MeV} \mathrm{p}$ & 7 & 38 & $2.66 \pm 0.27$ & $2.25 \pm 0.18$ & $2.58 \pm 0.36$ & $2.69 \pm 0.37$ \\
\hline $\mathrm{Cu}$ & 660 & $\mathrm{MeV} \mathrm{p}$ & 12 & 15 & $1.14 \pm 0.26$ & $1.11 \pm 0.24$ & $1.09 \pm 0.28$ & $1.12 \pm 0.30$ \\
\hline $\mathrm{Cu}$ & 680 & $\mathrm{MeV} \mathrm{p}$ & 31 & 16 & $0.80 \pm 0.14$ & $0.83 \pm 0.15$ & $0.74 \pm 0.13$ & $0.82 \pm 0.14$ \\
\hline $\mathrm{Cu}$ & 980 & $\mathrm{MeV} \mathrm{p}$ & 14 & 17 & $1.70 \pm 0.38$ & $1.90 \pm 0.35$ & $1.62 \pm 0.41$ & $1.85 \pm 0.50$ \\
\hline $\mathrm{Cu}$ & & $2 \mathrm{GeV} \mathrm{p}$ & 33 & 18 & $0.85 \pm 0.09$ & $1.00 \pm 0.10$ & $0.82 \pm 0.09$ & $0.92 \pm 0.10$ \\
\hline $\mathrm{Cu}$ & & $0 \mathrm{GeV} p$ & 16 & 19 & $0.95 \pm 0.06$ & $1.16 \pm 0.09$ & $0.92 \pm 0.07$ & $1.05 \pm 0.13$ \\
\hline $\mathrm{Cu}$ & & $7 \mathrm{GeV} \mathrm{p}$ & 43 & 20 & $1.09 \pm 0.08$ & $1.28 \pm 0.09$ & $1.08 \pm 0.09$ & $1.25 \pm 0.13$ \\
\hline $\mathrm{Cu}$ & 20 & $\mathrm{GeV} \mathrm{p}$ & 16 & 19 & $0.88 \pm 0.08$ & $1.07 \pm 0.10$ & $0.85 \pm 0.09$ & $0.98 \pm 0.15$ \\
\hline $\mathrm{Cu}$ & 24 & $\mathrm{GeV} p$ & 41 & 21 & $0.69 \pm 0.05$ & $0.81 \pm 0.07$ & $0.68 \pm 0.06$ & $0.77 \pm 0.09$ \\
\hline $\mathrm{Cu}$ & 25 & $\mathrm{GeV} p$ & 4 & 38 & $1.06 \pm 0.10$ & $1.15 \pm 0.07$ & $1.02 \pm 0.10$ & $1.08 \pm 0.06$ \\
\hline $\mathrm{Cu}$ & 29 & $\mathrm{GeV} p$ & 4 & 52 & $1.15 \pm 0.25$ & $1.46 \pm 0.28$ & $1.18 \pm 0.28$ & $1.69 \pm 0.38$ \\
\hline $\mathrm{Cu}$ & 30 & $\mathrm{GeV} \mathrm{p}$ & 16 & 19 & $0.87 \pm 0.08$ & $1.06 \pm 0.10$ & $0.84 \pm 0.08$ & $0.96 \pm 0.14$ \\
\hline $\mathrm{Zn}$ & 340 & $\mathrm{MeV} \mathrm{p}$ & 22 & 22 & $1.64 \pm 0.29$ & $1.77 \pm 0.33$ & $1.22 \pm 0.19$ & $1.33 \pm 0.23$ \\
\hline $\mathrm{As}$ & 49 & $\mathrm{GeV} p$ & 16 & 1 & $5.31 \pm 1.29$ & $8.66 \pm 2.64$ & $1.58 \pm 0.66$ & $1.83 \pm 0.78$ \\
\hline $\mathrm{As}$ & 103 & $\mathrm{GeV} p$ & 20 & 1 & $1.85 \pm 0.25$ & $2.27 \pm 0.37$ & $0.58 \pm 0.15$ & $0.60 \pm 0.16$ \\
\hline As & 170 & $\mathrm{GeV} \mathrm{p}$ & 22 & 1 & $3.10 \pm 0.25$ & $3.33 \pm 0.27$ & $2.27 \pm 0.24$ & $2.12 \pm 0.19$ \\
\hline As & 380 & $\mathrm{GeV} p$ & 52 & 24 & $2.17 \pm 0.26$ & $2.04 \pm 0.23$ & $1.18 \pm 0.19$ & $1.11 \pm 0.14$ \\
\hline As & 590 & $\mathrm{MeV} \mathrm{p}$ & 49 & 25 & $3.56 \pm 0.39$ & $3.22 \pm 0.32$ & $2.42 \pm 0.34$ & $2.65 \pm 0.40$ \\
\hline As & 2.9 & $\mathrm{GeV} \mathrm{p}$ & 8 & 26 & $1.30 \pm 0.80$ & $1.01 \pm 0.55$ & $1.01 \pm 0.57$ & $0.71 \pm 0.28$ \\
\hline $\mathbf{Y}$ & 240 & $\mathrm{MeV} \mathrm{p}$ & 24 & 27 & $1.43 \pm 0.30$ & $1.47 \pm 0.34$ & $0.57 \pm 0.14$ & $0.59 \pm 0.14$ \\
\hline $\mathrm{Zr}^{\mathrm{a}}$ & 1.8 & $\mathrm{GeV} \mathrm{p}$ & 9 & 53 & $3.17 \pm 1.92$ & $2.62 \pm 1.54$ & $2.00 \pm 1.35$ & $1.36 \pm 0.62$ \\
\hline $\mathrm{Nb}$ & 240 & $\mathrm{MeV} \mathrm{p}$ & 11 & 28 & $1.31 \pm 0.13$ & $1.26 \pm 0.12$ & $0.55 \pm 0.11$ & $0.59 \pm 0.10$ \\
\hline $\mathrm{Nb}$ & 320 & $\mathrm{MeV} \mathrm{p}$ & 11 & 28 & $1.34 \pm 0.14$ & $1.22 \pm 0.11$ & $0.69 \pm 0.12$ & $0.70 \pm 0.08$ \\
\hline $\mathrm{Nb}$ & 320 & $\mathrm{MeV} \alpha^{\mathrm{c}}$ & 11 & 28 & $1.73 \pm 0.27$ & $1.57 \pm 0.19$ & $0.89 \pm 0.16$ & $0.91 \pm 0.16$ \\
\hline $\mathrm{Nb}$ & 500 & $\mathrm{MeV} \mathrm{p}$ & 11 & 28 & $1.59 \pm 0.30$ & $1.38 \pm 0.19$ & $1.04 \pm 0.19$ & $0.97 \pm 0.11$ \\
\hline $\mathrm{Nb}$ & 500 & $\mathrm{MeV} \alpha^{\mathrm{c}}$ & 11 & 28 & $2.01 \pm 0.38$ & $1.74 \pm 0.29$ & $1.32 \pm 0.27$ & $1.22 \pm 0.15$ \\
\hline $\mathrm{Nb}$ & 720 & $\mathrm{MeV} \mathrm{p}$ & 11 & 28 & $1.79 \pm 0.43$ & $1.56 \pm 0.32$ & $1.33 \pm 0.32$ & $1.22 \pm 0.20$ \\
\hline $\mathrm{Nb}$ & 720 & $\mathrm{MeV} \alpha^{\mathrm{c}}$ & 11 & 28 & $2.16 \pm 0.73$ & $2.32 \pm 0.68$ & $1.86 \pm 0.63$ & $1.80 \pm 0.78$ \\
\hline $\mathrm{Nb}$ & 880 & $\mathrm{MeV} \alpha^{\mathrm{c}}$ & 11 & 28 & $2.07 \pm 0.72$ & $1.87 \pm 0.35$ & $1.62 \pm 0.38$ & $1.55 \pm 0.23$ \\
\hline
\end{tabular}

Table 9. 


\begin{tabular}{|c|c|c|c|c|c|c|c|c|c|}
\hline \multirow{3}{*}{$\begin{array}{c}\text { Target } \\
\text { Mo }\end{array}$} & \multirow{2}{*}{\multicolumn{2}{|c|}{ Irradiation }} & \multirow{3}{*}{$\begin{array}{l}\text { No. of } \\
\text { exp. } \\
\text { results }\end{array}$} & \multirow{3}{*}{$\frac{\text { Reference }}{53}$} & \multicolumn{5}{|c|}{ Average ratio $\sigma_{\exp } / \sigma_{\text {calc }}$} \\
\hline & & & & & CDMD-G & CDMD & \multicolumn{2}{|c|}{ IDED-G } & \multirow{2}{*}{$\begin{array}{c}\text { IDED } \\
1.43 \pm 0.16\end{array}$} \\
\hline & 1.8 & $\mathrm{GeV} p$ & & & $1.77 \pm 0.25$ & $1.52 \pm 0.15$ & $1.47 \pm$ & 0.24 & \\
\hline $\mathrm{Ru}^{\mathrm{a}}$ & 1.8 & $\mathrm{GeV} \mathrm{p}$ & 9 & 53 & $1.90 \pm 0.40$ & $1.57 \pm 0.30$ & $2.31 \pm$ & 0.45 & $2.11 \pm 0.55$ \\
\hline $\mathrm{Ag}$ & 340 & $\mathrm{MeV} \mathrm{p}$ & 48 & 29 & $2.10 \pm 0.33$ & $1.93 \pm 0.29$ & $0.79 \pm$ & 0.12 & $0.82 \pm 0.12$ \\
\hline $\mathrm{Ag}$ & 480 & $\mathrm{MeV} \mathrm{p}$ & 36 & 30 & $14.4 \pm 2.2$ & $11.3 \pm 1.6$ & $6.4 \pm$ & 0.9 & $6.5 \pm 0.9$ \\
\hline In & 2.9 & $\mathrm{GeV} \mathrm{p}$ & 14 & 31 & $3.70 \pm 1.00$ & $4.11 \pm 0.94$ & $3.17 \pm$ & 0.94 & $2.49 \pm 0.36$ \\
\hline $\mathrm{Sb}$ & 100 & $\mathrm{MeV} d$ & 8 & 32 & $3.08 \pm 0.78$ & $7.47 \pm 2.92$ & $0.74 \pm$ & 0.58 & $0.41 \pm 0.24$ \\
\hline $\mathrm{Sb}$ & 190 & $\mathrm{MeV} \mathrm{d}$ & 24 & 32 & $2.59 \pm 0.70$ & $3.33 \pm 0.99$ & $0.63 \pm$ & 0.30 & $0.32 \pm 0.10$ \\
\hline $\mathrm{Sb}$ & 380 & $\mathrm{MeV} \alpha^{\mathrm{d}}$ & 18 & 32 & $1.35 \pm 0.37$ & $1.34 \pm 0.72$ & $0.51 \pm$ & 0.23 & $0.32 \pm 0.09$ \\
\hline $\mathrm{Cs}$ & 100 & $\mathrm{MeV} \mathrm{p}$ & 8 & 33 & $4.93 \pm 2.53$ & $14.5 \pm 9.1$ & $2.66 \pm$ & 2.84 & $0.77 \pm 0.57$ \\
\hline Cs & 150 & $\mathrm{MeV} \mathrm{p}$ & 9 & 33 & $1.40 \pm 0.48$ & $2.82 \pm 1.35$ & $0.22 \pm$ & 0.14 & $0.17 \pm 0.09$ \\
\hline $\mathrm{Cs}$ & 240 & $\mathrm{MeV} \mathrm{p}$ & 15 & 33 & $4.75 \pm 2.76$ & $6.78 \pm 3.77$ & $0.90 \pm$ & 0.52 & $0.60 \pm 0.27$ \\
\hline $\mathrm{La}^{\mathrm{b}}$ & 590 & $\mathrm{MeV} \mathrm{p}$ & 14 & 39 & $15.5 \pm 8.9$ & \pm 11 & 38 & 38 & $3.46 \pm 1.24$ \\
\hline $\mathrm{La}^{\mathrm{b}}$ & 18 & $\mathrm{GeV} \mathrm{p}$ & 14 & 39 & \pm 39 & \pm 32 & 350 & 50 & $5.18 \pm 3.22$ \\
\hline $\mathrm{Hf}$ & 660 & $\mathrm{MeV} \mathrm{p}$ & 25 & 5 & $1.90 \pm 0.90$ & $1.81 \pm 0.66$ & $0.69 \pm$ & 0.23 & $0.53 \pm 0.19$ \\
\hline $\mathrm{Ta}$ & 340 & $\mathrm{MeV} \mathrm{p}$ & 23 & 54 & $16.5 \pm 9.0$ & $12.8 \pm 6.9$ & $1.04 \pm$ & 0.54 & $1.07 \pm 0.48$ \\
\hline $\mathrm{Ta}$ & 5.7 & $\mathrm{GeV} \mathrm{p}$ & 27 & 4 & $3.09 \pm 0.44$ & $2.60 \pm 0.31$ & $1.47 \pm$ & 0.17 & $1.77 \pm 0.20$ \\
\hline $\mathrm{Ta}$ & 18 & $\mathrm{GeV} \mathrm{p}$ & 7 & 39 & $0.54 \pm 0.07$ & $1.42 \pm 0.22$ & $0.51 \pm$ & 0.09 & $0.38 \pm 0.04$ \\
\hline $\mathrm{Au}$ & 18 & $\mathrm{GeV} \mathrm{p}$ & 6 & 39 & $1.89 \pm 0.65$ & $2.78 \pm 0.42$ & $1.08 \pm$ & 0.25 & $1.04 \pm 0.27$ \\
\hline $\mathrm{Bi}$ & 380 & $\mathrm{MeV} p$ & 34 & 34 & $1.60 \pm 0.49$ & $1.44 \pm 0.23$ & $1.90 \pm$ & 0.41 & $0.62 \pm 0.07$ \\
\hline $\mathrm{Bi}$ & 480 & $\mathrm{MeV} \mathrm{p}$ & 17 & 15,16 & $2.81 \pm 1.74$ & $3.69 \pm 2.01$ & $6.52 \pm$ & 3.83 & $1.72 \pm 0.84$ \\
\hline $\mathrm{Bi}$ & 660 & $\mathrm{MeV} \mathrm{p}$ & 31 & 35,36 & $6.95 \pm 2.20$ & $6.45 \pm 1.82$ & $6.29 \pm$ & 2.08 & $2.58 \pm 0.62$ \\
\hline
\end{tabular}

a Not used for the $\sigma$-analysis because the target is considerably removed from the stability line.

b Not used for the $\sigma$-analysis because these distributions are quite anomalous with relatively large yields for heavy isotopes (cf. Ref. ${ }^{39}$ ).

c The total inelastic cross-section taken to be $1630 \mathrm{mb}{ }^{55}$.

Table 9. Average ratio between experimental and calculated cross-sections.

included for nuclides which are not formed in proton-induced reactions. Also the lower limit will tend to include cross-sections for products which are not formed. The error introduced by putting $\sigma=\sigma_{i}$ will be especially large at low irradiation energies. For the IDED (-G) distributions the error introduced by integrating up to $Z=Z_{\mathrm{t}}$ is partly compensated by omitting the yields for $Z=Z_{\mathrm{t}}+1$, i. e. the $(\mathrm{p}, x \mathrm{n})$ reactions.

The $\left(\sigma_{\exp } / \sigma_{\text {calc }}\right)_{\mathrm{Av}}$ values of Table 9 can serve as an estimate of $\hat{\sigma} / \sigma_{i}$. For the $\operatorname{CDMD}(-G)$ distributions an inspection of the table shows that $\left(\sigma_{\text {exp }} / \sigma_{\text {calc }}\right)_{\mathrm{Av}}$, for a given target, is reasonably constant above about $250 \mathrm{MeV}$, but that it increases with decreasing irradiation energy. Besides, there is a definite dependence on target mass. The $\left(\sigma_{\text {exp }} / \sigma_{\text {calc }}\right)_{\text {Av }}$ values can be fitted to the empirical formula

$$
\begin{aligned}
& \widehat{\sigma}=\sigma_{i} \times f_{1}\left(A_{\mathrm{t}}\right) \times f_{2}(E), \\
& f \hat{\mathrm{e}}\left(A_{\mathrm{t}}\right)=e^{-g^{\prime}+h^{\prime} A_{\mathrm{t}}} \text {, } \\
& f_{2}(E)=e^{k^{\prime}-l^{\prime} E} \text { for } E<E_{\mathrm{c}} \text {, } \\
& f_{2}(E)=1 \quad \text { for } E \geqq E_{\mathrm{c}} \text {. }
\end{aligned}
$$

A "least squares" analysis applied to $\log \left(\hat{\sigma} / \sigma_{i}\right)$ yields the values of the constants and of $E_{\mathrm{c}}$ given in

50 J. Cumming, G. Friedlander, J. Hudis, and A. M. Poskanzer, Phys. Rev. 127, 950 [1962ך.

51 G. V.S. Rayudu, private communication [1964].

52 N. T. Porile and S. TANaka, Brookhaven National Laboratory Report BNL-7633 [1964].
Table 10. In this analysis all experimental data were used with a few exceptions (noted in Table 9).

For the IDED (-G) distributions no systematic trend of $\left(\sigma_{\exp } / \sigma_{\text {calc }}\right)_{\mathrm{Av}}$ is found in Table 9 , and $\hat{\sigma}=\sigma_{i}$ is therefore retained as an approximation.

\subsection{Systematic deviations from the cross-section formulas}

Predictions from the four different cross-section formulas can now be compared with experimental results in order to single out the most appropriate formula. For this, $\sigma_{\exp } / \sigma_{\text {calc }}$ has been calculated for about 1200 experimentally determined cross-sections. The average of these values and its standard deviation has then been computed for each nuclide studied experimentally under the assumption that all experimental determinations have the same weight. These averages are then grouped in different ways for a number of statistical tests.

An important test checks the form of the charge distributions and the isotopic distributions. The spallation products are then grouped into eight different groups according to the magnitude of the calculated cross-section (Table 11). The average

53 N. T. Porile and L. B. Church, Phys. Rev. 133, B 310 [1964].

54 W. E. Nervik and G. T. Seaborg, Phys. Rev. 97, 1092 [1955].

55 J. R. Huizenga and G. Igo, Nucl. Phys. 29, 462 [1962]. 


\begin{tabular}{|c|c|c|c|c|c|}
\hline Distribution & $g^{\prime}$ & $h^{\prime}$ & $k^{\prime}$ & $l^{\prime}$ & $E_{\mathrm{c}}$ \\
\hline \multirow[t]{2}{*}{ CDMD-G } & 0.37 & 0.0076 & 1.24 & 0.0044 & $280 \mathrm{MeV}$ \\
\hline & \pm 0.16 & \pm 0.0023 & \pm 0.32 & \pm 0.0018 & \\
\hline \multirow[t]{2}{*}{ CDMD } & 0.25 & 0.0074 & 1.73 & 0.0071 & $240 \mathrm{MeV}$ \\
\hline & \pm 0.12 & \pm 0.0016 & \pm 0.35 & \pm 0.0018 & \\
\hline
\end{tabular}

Table 10. Constants defining the parameter $\hat{\sigma}$.

values of $\sigma_{\text {exp }} / \sigma_{\text {calc }}$ corresponding to the different groups are given in Figs. $4 \mathrm{a}-4 \mathrm{~d}$. (Groups I and II have been joined because of the small number of experimental results belonging to Group I.) It is immediately evident from the figure that the $\operatorname{IDED}(-G)$ distributions are incorrect. For these

\begin{tabular}{|c|l|l|l|l|}
\hline \multirow{2}{*}{ Group } & \multicolumn{2}{|c|}{$\sigma / \sigma_{\mathrm{p}}$} & & \\
\cline { 2 - 3 } & $\begin{array}{c}\text { lower } \\
\text { limit }\end{array}$ & $\begin{array}{c}\text { upper } \\
\text { limit }\end{array}$ & $\operatorname{CDMD}(\mathrm{G})$ & $\operatorname{IDED}(\mathrm{G})$ \\
\hline I & 0 & 0.001 & $Z>Z_{\mathrm{p}}$ & $A<A_{\mathrm{p}}$ \\
II & 0.001 & 0.01 & $Z>Z_{\mathrm{p}}$ & $A<A_{\mathrm{p}}$ \\
III & 0.01 & 0.1 & $Z>Z_{\mathrm{p}}$ & $A<A_{\mathrm{p}}$ \\
IV & 0.1 & 1 & $Z>Z_{\mathrm{p}}$ & $A<A_{\mathrm{p}}$ \\
V & 0.1 & 1 & $Z<Z_{\mathrm{p}}$ & $A>A_{\mathrm{p}}$ \\
VI & 0.01 & 0.1 & $Z<Z_{\mathrm{p}}$ & $A>A_{\mathrm{p}}$ \\
VII & 0.001 & 0.01 & $Z<Z_{\mathrm{p}}$ & $A>A_{\mathrm{p}}$ \\
VIII & 0 & 0.001 & $Z<Z_{\mathrm{p}}$ & $A>A_{\mathrm{p}}$ \\
\hline
\end{tabular}

Table 11. Groups for checking the charge distribution and isotopic distribution ( $\sigma_{\mathrm{p}}=$ peak value of distribution concerned).

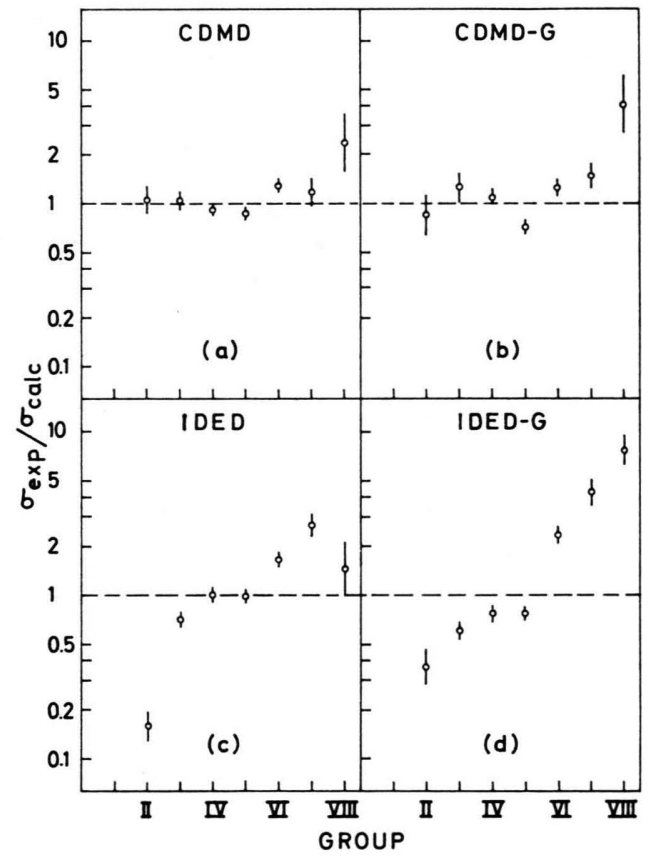

Fig. 4. Statistical test of the form of the charge distribution for CDMD (a) and CDMD-G (b), and of the form of the isotopic distribution for IDED (c) and IDED-G (d) . there is a systematic increase of $\sigma_{\text {exp }} / \sigma_{\text {calc }}$ when going from one group to the next one showing that the calculated values are too high for light isotopes and too low for heavy isotopes of an element. Good agreement with experimental results is only obtained for isotopes in the vicinity of $A_{\mathrm{p}}$. Although the conclusion is that the assumption about a symmetric isotopic distribution is false, the IDED (-G) nevertheless approximate the experimental cross-sections quite well, and they can be useful for certain purposes.

The CDMD (-G) distributions, on the other hand, are in better agreement with experiments. In fact, Student's t-test with a significance level of 0.05 (more than 5\% chance that the average ratio $\sigma_{\text {exp }} / \sigma_{\text {calc }}$ is unity) shows that almost all groups are compatible with an average value of unity for CDMD. The only exception is the group VI. For CDMD-G the agreement is not so good, and the three groups V, VII, and VIII are found to be significantly different from unity when using the same criterion as above. This test thus gives preference for CDMD indicating that the charge distribution does not fall off as rapidly as a Gaussian distribution far out at the wings. For a definite choice one would wish more experimental data for nuclides far from stability. One such case is $\mathrm{Ca}^{49}$. Its cross-section has been measured at $590 \mathrm{MeV}$, with copper as target, by Sörensen ${ }^{56}$, and it is about $7.5 \mu \mathrm{b}$. CDMD gives $0.8 \mu \mathrm{b}$ and CDMD-G $0.1 \mu \mathrm{b}$. Both these values are too low, but the CDMD prediction is the better one. Thus CDMD seems to be the best choice for the cross-section distribution, and it will be used in the following tests.

Another important test is to check the possible dependence on the nuclear type. In this case the $\left(\sigma_{\text {exp }} / \sigma_{\text {calc }}\right)$ values are grouped according to the type of the product: $Z_{\text {odd }}-N_{\text {odd }}, Z_{\text {odd }}-N_{\text {even }}, Z_{\text {even }}-N_{\text {odd }}$, and $Z_{\text {even }}-N_{\text {even }}$. The results are tabulated in Table 12. With few exceptions the average values are compatible with a value of unity, and no significant dependence on nuclear type is found.

56 G. Sörensen, private communication [1964]. 


\begin{tabular}{|l|c|c|c|c|}
\hline Product range & $Z_{\text {odd }}-N_{\text {odd }}$ & $Z_{\text {odd }}-N_{\text {even }}$ & $Z_{\text {even }}-N_{\text {odd }}$ & $Z_{\text {even }}-N_{\text {even }}$ \\
\hline$Z \leqq 30$ & $0.91 \pm 0.05$ & $1.17 \pm 0.08$ & $0.89 \pm 0.07$ & $1.19 \pm 0.11$ \\
$30<Z \leqq 60$ & $1.04 \pm 0.12$ & $0.95 \pm 0.16$ & $1.19 \pm 0.16$ & $1.73 \pm 0.35$ \\
$60<Z$ & $0.56 \pm 0.21$ & $0.73 \pm 0.19$ & $0.76 \pm 0.22$ & $0.83 \pm 0.30$ \\
all $Z$ & $0.90 \pm 0.04$ & $1.05 \pm 0.06$ & $0.95 \pm 0.06$ & $1.32 \pm 0.14$ \\
\hline
\end{tabular}

Table 12. Average value of $\sigma_{\mathrm{exp}} / \sigma_{\text {calc }}$ as a function of nuclear type (CDMD-distribution).

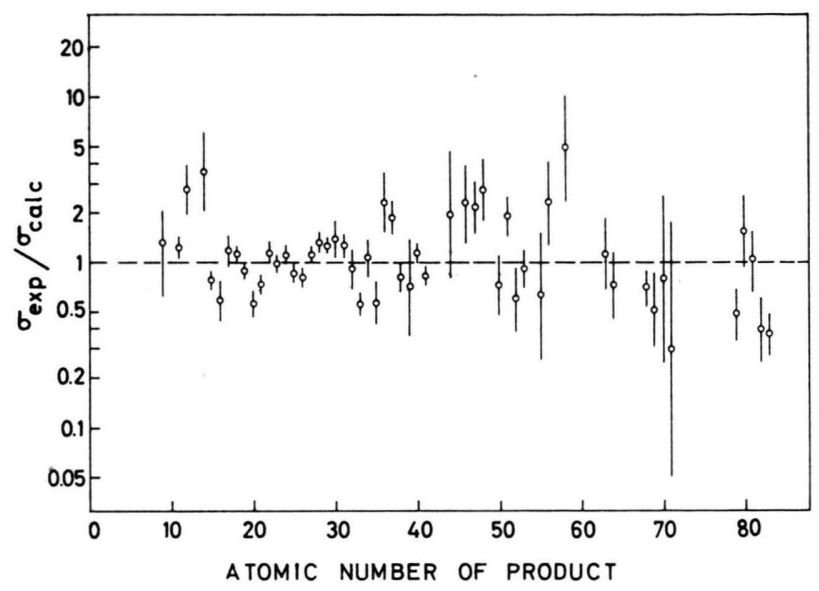

Fig. 5. Ratio between experimental and calculated cross-sections as a function of the atomic number of the spallation product.

In Fig. 5 the value $\sigma_{\text {exp }} / \sigma_{\text {calc }}$, averaged over all isotopes measured, has been plotted versus the atomic number of the spallation product for cases with at least four experimental determinations. These average values are significantly different from unity only for the following nine elements: $\mathrm{Mg}, \mathrm{Cu}, \mathrm{Rb}, \mathrm{Cd}$, and $\mathrm{Sb}$ (too high) and $\mathrm{Ca}, \mathrm{Sc}, \mathrm{As}$, and $\mathrm{Bi}$ (too low). For 44 elements they are consistent with a value of unity.

Finally, it is found that the cross-section formula predicts the cross-sections within a factor of 3 , on the average (within a factor of 2.4 , if only products with $Z \leqq 30$ are included). This might seem to be a rather bad agreement, but it must be remembered that the range of cross-sections covered is very large: a factor of more than $10^{6}$. Furthermore, the experimental determinations are quite often very uncertain, and the precision is probably considerably better than the factor of 3 indicates.

\section{Estimation of spallation cross-sections}

In section 4 it has been shown that the CDMD-distribution approximates the spallation cross-sections reasonably well. Using Eq. (25) (with small terms in the denominator neglected), Eqs. (28) and (29) and Table 6, the following practical formula for proton or neutron-induced reactions is obtained (various factors depending on the target have been combined into the function $\left.F\left(A_{\mathrm{t}}\right)\right)$ :

$$
\begin{aligned}
P A_{\mathrm{t}} \geqq 1: \sigma(Z, A) \sim F\left(A_{\mathrm{t}}\right) & \times f_{2}(E) \times \frac{P e^{-P\left(A_{\mathrm{t}}-A\right)}}{1-\left[0.3 /\left(P \frac{\left.\left.A_{\mathrm{t}}\right)\right]}{1}\right.\right.} \\
& \times e^{-R\left|Z-S A+T A^{2}\right|^{\frac{3}{2}}}, \quad(30)
\end{aligned}
$$

with $S=0.486 ; T=0.00038$; and $P, R, F\left(A_{\mathrm{t}}\right)$, and $f_{2}(E)$ taken from Figs. 1, 2, and 6. As an illustration, this formula has been used to compute cross-sections for a number of spallation products from copper. Four mass regions were chosen: $\sim 60$, $\sim 50, \sim 40$, and $\sim 30$, and in each region the crosssection of one product close to the peak of the charge distribution (corresponding to Groups IV and V of Table 11) and that of one or two products at the wings (Groups II - III and VI - VII) have been calculated for different irradiation energies. The ex-

$F\left(A_{\mathrm{t}}\right)$

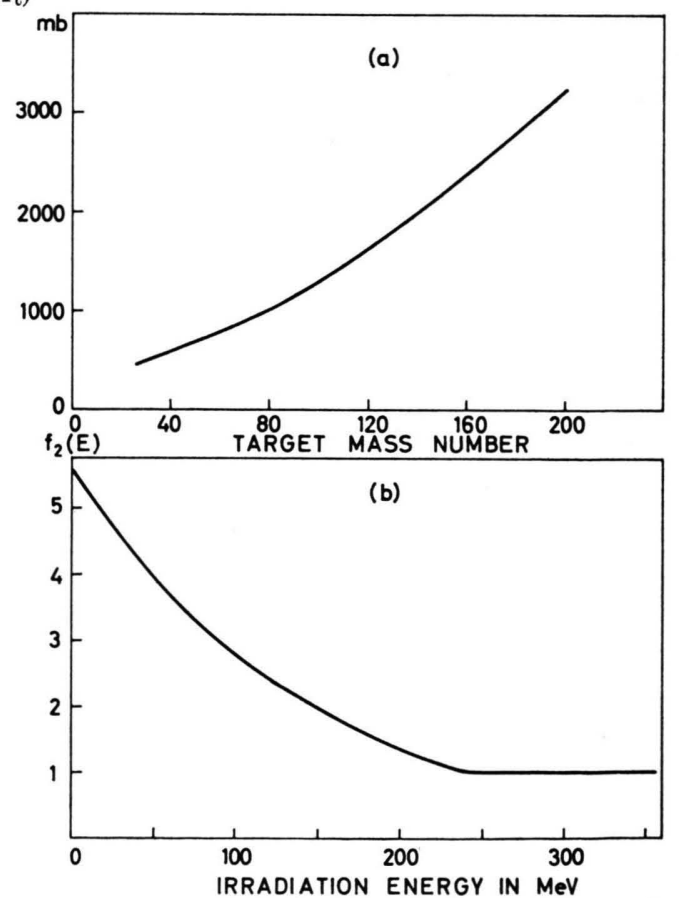

Fig. 6. (a) Function $F\left(A_{\mathrm{t}}\right)$ versus the target mass number $A_{\mathrm{t}}$. (b) Function $f_{2}(E)$ versus irradiation energy. 
citation functions thus obtained have been plotted in Figs. $7 \mathrm{a}$ to $7 \mathrm{~d}$ (bold lines) together with smooth curves through experimental determinations from the irradiation of copper with protons of energy 90 and $190 \mathrm{MeV}^{12}, 340 \mathrm{MeV}^{13}, 680 \mathrm{MeV}^{16}, 980 \mathrm{MeV}^{17}$, $2.2 \mathrm{GeV}^{18}, 3.0 \mathrm{GeV}^{19}, 5.7 \mathrm{GeV}^{20}, 20 \mathrm{GeV}^{19}$, $24 \mathrm{GeV}^{21}$, and $30 \mathrm{GeV}^{19}$ (fine lines). Apparently, the experimental excitation functions are quite well reproduced both in form and on the absolute scale.

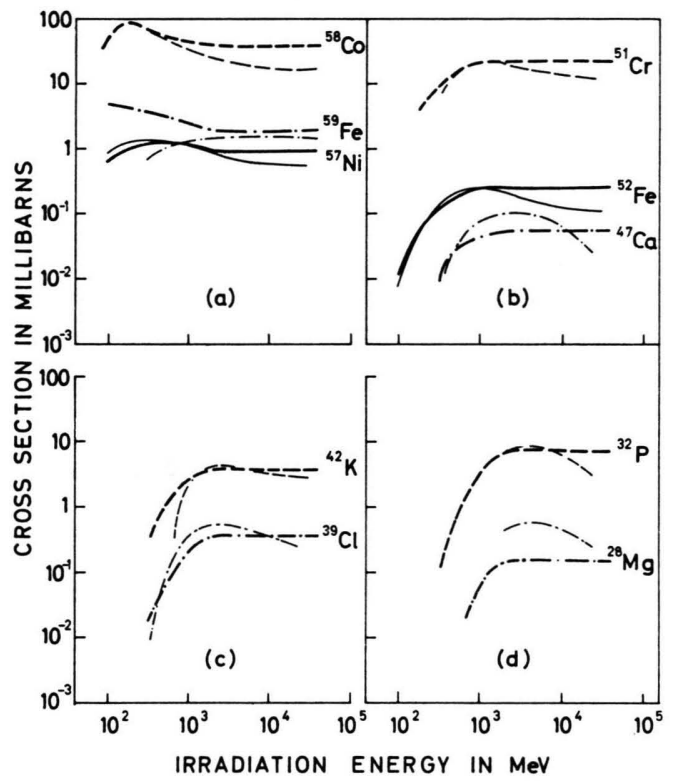

Fig. 7. Comparison between calculated excitation functions (bold line) and experimental ones (fine line of the same character) for various spallation products from copper.

In using the cross-section formula its limitations have to be kept in mind. In particular, its usefulness for very light and for very heavy targets has not yet been established owing to lack of experimental data. Also, deviations are to be expected for targets far off stability because some memory of the starting point will remain even after a long evaporation chain ${ }^{53}$. It must be remembered that the parameters of the formula have been derived to fit distributions from natural targets around stability and not for extreme cases.

\section{Use of cross-section estimates}

In the preceding sections a procedure has been developed by which spallation cross-sections can be estimated on the absolute scale with fair accuracy

57 M. Honda and J. R. Arnold, Geochim. Cosmochim. Acta 23, 219 [1961]. for a wide range of irradiation conditions. Such estimates are often of great value. A few examples will make this clear.

Many accelerators are used to a great extent for production of radio-isotopes for various purposes. It is, then, of practical interest to be able to estimate cross-sections in order to find the best irradiation conditions and thus use the accelerator in an efficient way. An inspection of the cross-section formula indicates that for a given combination of target and spallation product, the maximum yield is obtained for

$$
P \sim \frac{1}{A_{\mathrm{t}}-A}
$$

The corresponding irradiation energy is obtained from Eq. (15) or Fig. 1. The maximum (independent) yield is given by

CDMD: $\{\sigma(Z, A)\}_{\max }$

$\leq \frac{F\left(A_{\mathrm{t}}\right) f_{2}(E) \exp \left\{-1-R\left|Z-S A+T A^{2}\right|^{3 / 2}\right\}}{\left(A_{\mathrm{t}}-A\right)\left[1-0.3\left(A_{\mathrm{t}}-A\right) / A_{\mathrm{t}}\right]} \mathrm{mb}$

where the inequality sign is valid for $E \geqq E_{0}$ (Table 3).

All target materials contain a certain amount of impurities. In cases where reactions having very low cross-sections are being studied, it is necessary to estimate the contribution to the yield of the nuclide in question originating from spallation reactions in the impurities.

An important application of estimating spallation yields is connected to the study of cosmic-ray induced activities in meteorites. In recently fallen meteorites, for example, the amount of a large number of radioactive spallation products has been measured ${ }^{57}$. If the spallation cross-sections are known, one can get information not only about the cosmic-ray intensity but also on its energy distribution.

As a further example, the determination of the half-life of long-lived nuclides might be mentioned. If these are made by spallation and the production cross-section is known, then the half-life can be easily deduced from the disintegration rate ${ }^{3}$.

Another aspect of the use of cross-section formulas is in connection with estimates of radiation doses to be expected from activated materials, for example accelerator parts. For such estimates knowledge about spallation cross-section is necessary, and the cross-section formula becomes a very convenient tool in the calculations ${ }^{58}$.

58 M. BARBIER, private communication [1965]. 